\title{
Modeling of Fracture Width and Conductivity in Channel Fracturing With Nonlinear Proppant-Pillar Deformation
}

\author{
Haiyan Zhu, Chengdu University of Technology, State Key Laboratory of Oil and Gas Reservoir Geology \\ and Exploitation, and Institute of Mechanics, Chinese Academy of Sciences; \\ Ya-Pu Zhao, Institute of Mechanics, Chinese Academy of Sciences and University of Chinese Academy of Sciences; \\ Yongcun Feng, University of Texas at Austin; Haowei Wang, Southwest Petroleum University; \\ Liaoyuan Zhang, Sinopec Shengli Oilfield Company; and John D. McLennan, University of Utah
}

\section{Summary}

Channel fracturing acknowledges that there will be local concentrations of proppant that generate high-conductivity channel networks within a hydraulic fracture. These concentrations of proppant form pillars that maintain aperture. The mechanical properties of these proppant pillars and the reservoir rock are important factors affecting conductivity. In this paper, the nonlinear stress/strain relationship of proppant pillars is first determined using experimental results. A predictive model for fracture width and conductivity is developed when unpropped, highly conductive channels are generated during the stimulation. This model considers the combined effects of pillar and fracture-surface deformation, as well as proppant embedment. The influence of the geomechanical parameters related to the formation and the operational parameters of the stimulation are analyzed using the proposed model. The results of this work indicate the following:

1. Proppant pillars clearly exhibit compaction in response to applied closure stress, and the resulting axial and radial deformation should not be ignored in the prediction of fracture conductivity.

2. There is an optimal ratio (approximately 0.6 to 0.7 ) of pillar diameter to pillar distance that results in a maximum hydraulic conductivity regardless of pillar diameter.

3. The critical ratio of rock modulus to closure stress currently used in the industry to evaluate the applicability of a channelfracturing technique is quite conservative.

4. The operational parameters of fracturing jobs should also be considered in the evaluation.

\section{Introduction}

In conventional hydraulic-fracturing treatments, it is presumed that proppant is distributed uniformly in the fracturing fluid and generates a uniform proppant pack in the fracture (left-hand side of Fig. 1). The propped fracture serves as a high-conductivity channel facilitating fluid flow from the reservoir to the well. Channel fracturing is a new fracturing concept, and replaces a nominally homogeneous proppant pack in the fracture with a heterogeneous structure containing a network of open channels (Fig. 1, right) (Gillard et al. 2010). This channel-like structure is achieved by using fiber-laden fluids or self-aggregating proppant together with a pulsed-pumping strategy. In channel fracturing, the interaction between the proppant and fracture surfaces is a "point" contact, in contrast to the "surface" contact assumed to exist in conventional fracturing. As a result, channel fracturing creates a network of open channels and dramatically increases fracture conductivity (Zhu et al. 2018).

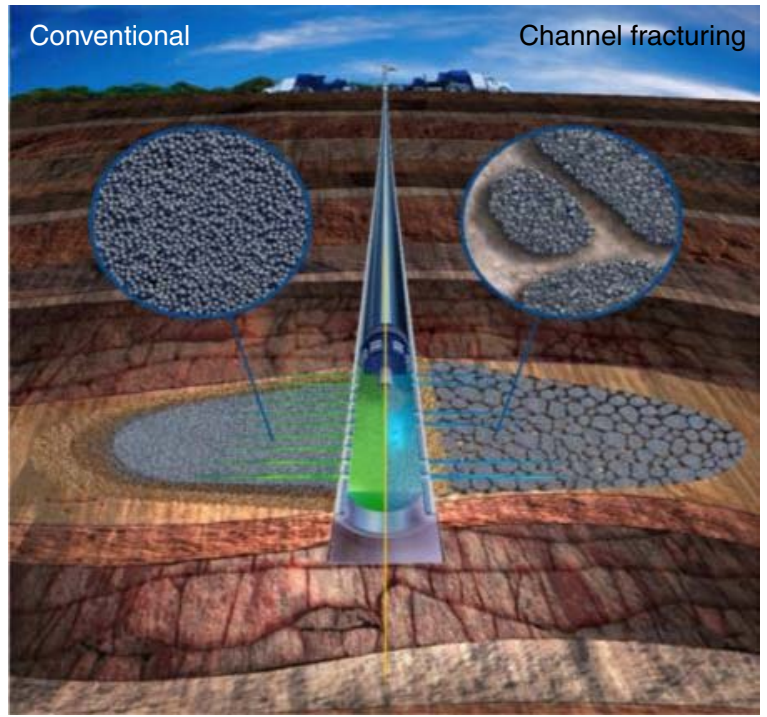

Fig. 1-Schematic of (left) conventional fracturing and (right) channel fracturing (Gillard et al. 2010). 
It has been reported that the conductivity of a "channel fracture" can be several orders of magnitude higher than that of a conventional fracture. Since the introduction of channel fracturing in 2010 (Gillard et al. 2010), this technology has been used several thousand times worldwide and good stimulation results have been documented. Valenzuela et al. (2012) reported the application of channel fracturing in a sandstone reservoir in Burgos Basin, Mexico, with a 32\% increase in initial gas production and a 19\% increase in 6-month accumulated production. Channel fracturing was also used in six conventional oil wells in the Talinskoe Oil Field in western Siberia, Russia, and a 51\% increase in oil production was achieved. This success demonstrates that channel fracturing is also applicable to conventional reservoirs (Kayumov et al. 2012). In an application of channel fracturing in the desert of western Egypt, an 89\% increase in initial production was observed (Gawad et al. 2013). A production increase of $29 \%$ was reported after applying channel-fracturing stimulation in Taylakovskoe Field in Siberia (Valiullin et al. 2015). Li et al. (2015a) reported stimulation results for channel fracturing in tight oil and gas reservoirs in Ordos Basin, China; the production of oil wells increased by 1.4 times and gas-well production increased by three to five times.

In a channel-fracturing treatment, proppant stages and clean-fluid slugs are injected into the formation alternately. Discrete proppant conglomerates (usually referred to as proppant pillars after closure) settle in the fracture and keep the fracture open. After the treatment, the fracture tends to close under the in-situ stress. Consequently, the proppant pillars will deform and partially embed into the rock, reducing the fracture opening. The fracture will be "pinched" in the area between proppant conglomerates (Fig. 2), resulting in nonuniform fracture opening, and further affecting fluid flow through the fracture. The capability of the proppant pillars to support the fracture surfaces is essential for maintaining high fracture conductivity. To ensure and promote successful application of the channel-fracturing technique, a systematic investigation has been performed to consider the stress/strain response of isolated proppant pillars, fracturewidth distribution between pillars, and fracture conductivity.

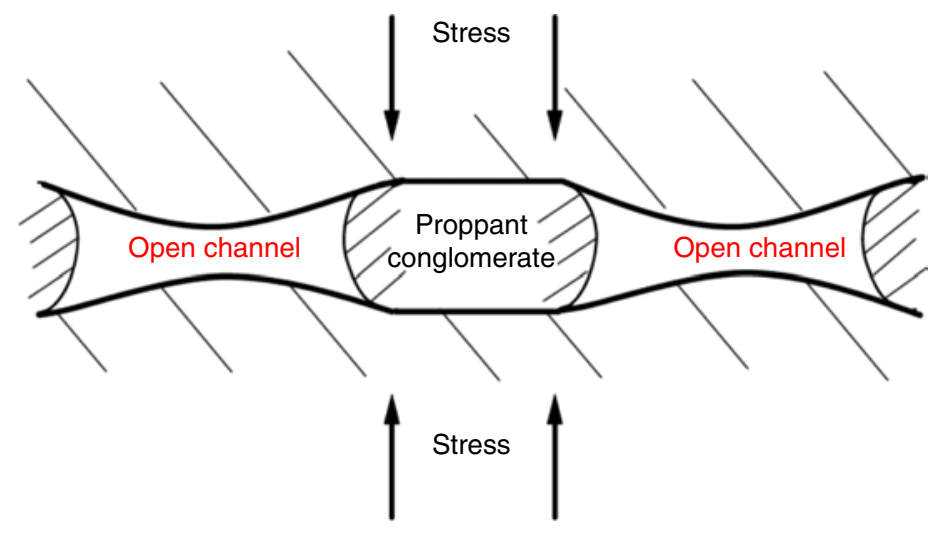

Fig. 2-Schematic of nonuniform fracture opening in channel fracturing (Kayumov et al. 2012).

In recent years, researchers have studied the mechanical characteristics of proppant pillars and the conductivity of channel fractures. This research has been performed both theoretically and experimentally. Gillard et al. (2010) measured the conductivity of channel fractures by placing proppant pillars between two parallel plates to mimic a channel fracture. Using a similar method, Nguyen et al. (2014) investigated the influences of proppant type, pillar number, pillar-layout pattern, and closure stress on pillar deformation and fracture conductivity. Tang et al. (2018) conducted a comprehensive experimental and numerical investigation into the behavior of proppant in inhomogeneous rocks. Their studies show that the influence of fracturing fluid on proppant embedment is more significant for high proppant concentrations, and the embedment under water-saturated conditions is higher than that under oil-saturated conditions.

Considering embedment and the axial deformation of proppant pillars, Zhang (2014) and Zhang and Hou (2016) derived an analytical solution of fracture width and conductivity for channel fracturing. Yan et al. (2016) developed a fracture-conductivity model for channel fractures using the Darcy-Brinkman equation, assuming that the proppant pillars experience only axial deformation. On the basis of Hertz contact theory, Zheng et al. (2017) obtained expressions for fracture width and fracture conductivity characteristic of channel fracturing. Hou et al. (2016a) developed a predictive model for fracture conductivity using the classic cubic law for fluid flow between two parallel plates. Starting from an examination of the interaction between a single proppant particle and the adjacent fracture surface, Guo et al. (2017) derived an analytical model for proppant embedment and fracture conductivity applicable to channel fracturing. Hou et al. (2016b) considered the proppant pillar as a rigid material and the rock as a linear elastic material; the fracture width of the open channel was established using the elastic half-space analytical solution of Hertz contact theory. Meyer et al. (2014) also used the elastic half-space analytical solution of Hertz contact theory; the fracture width of the open channel was established considering the different geometries and distributions of the proppant pillars, and the fracture-conductivity model was deduced using Darcy's law and the equivalent-seepage-resistance principle. However, all these existing models for calculating fracture width and conductivity neglect the deformation of the fracture surfaces, and assume that the final fracture width is equal to the initial fracture width minus the length reduction of the pillars and minus two times the proppant embedment. Moreover, nonlinear stress/strain relationships for proppantpillar deformation have not been considered. In other words, all the existing models assume that proppant pillars behave as linearly elastic materials. This is probably an unreasonable assumption for any pillar configuration beyond a monolayer.

Models that do not consider nonlinear stress/strain characteristics of the proppant pillars and the synchronous deformation of fracture surfaces and proppant pillars might predict unrealistically large fracture width and conductivity. To this end, this paper reports an experimental investigation into the deformation of proppant pillars. The aim is to establish more-realistic nonlinear stress/strain relationships for proppant pillars using experimental results. Next, we derived analytical solutions for proppant embedment and the resultant fracture width by combining the stress/strain relationship for the pillars and the elastic contact theory for the adjacent rock. Finally, an integrated model for predicting fracture width and conductivity was developed for channel fracturing. This model accounts for the nonlinear mechanical behavior of the proppant pillars and the nonuniform deformation of the fracture surfaces. The influences of formation properties and operational parameters on channel fracturing are then evaluated using the proposed model. 


\section{Model Development}

This work develops an analytical model for quantifying fracture width and fracture conductivity in channel fractures. The model assumes that fracture width is controlled by three deformation components: nonlinear deformation of the proppant pillar, uneven deformation of the fracture surface, and embedment of the proppant pillar in rock.

During the fracture-closing process, large nonlinear deformation in the proppant pillar occurs, which is the main factor affecting fracture width. The macroscopic nonlinear deformation of the proppant pillar is actually caused by proppant rearrangement in the pillar. Nonlinear deformation in the proppant pillar could keep evolving with particle rearrangement until a mechanically stable state is reached. The embedment of the proppant pillar in rock and the deformation of the fracture surface also affect fracture width, but they usually have a much-smaller effect compared with the deformation of the proppant pillar. This is very different from traditional hydraulic fractures fully filled with proppants, in which embedment and fracture-surface deformation are the main factors accounting for fracture closing. Although these two effects are not significant for channel fractures, the newly proposed model includes them for the accuracy of the model.

Nonlinear Deformation of Proppant Pillars. To better understand the stress/strain behavior of proppant pillars, we experimentally investigated their deformation and failure characteristics under different closure stresses using the uniaxial compression test. The axial and radial deformations and the stress/strain curves for proppant pillars during loading (to simulate application and maintenance of the in-situ stresses) were obtained.

The American Petroleum Institute recommended practices for hydraulic-conductivity measurement were used as the overall basis for the experimental study (API RP 61 1989). To minimize boundary effects, the diameter of the artificial proppant pillars constructed in the conductivity apparatus was less than one-half the width of the experimental cell. Fig. 3 shows an example of these proppant pillars before and after the test. The pillars were made by mixing 40/70-mesh ceramic proppants with fibers and gluing them together with a liquid glue. The weight of the fibers is approximately $4 \%$ of the weight of the ceramic proppants in each pillar. The proppant pillars are then dried for 4 hours in an oven with a temperature of $60^{\circ} \mathrm{C}$. Five proppant pillars with the same initial dimensions (10-mm diameter and 10-mm height) were placed in the experimental cell to conduct the uniaxial compressive test. In the test, an FCES-100 fracture-conductivity test system was used and the axial and radial deformations of the proppant pillars were measured. The axial deformation was measured by a displacement sensor equipped on the loading axis of the FCES-100 test system, while the radial deformation is measured manually after each closing stress. Pillar behavior was tested under seven closure stresses (1, 6.9, 13.8, 20.7, 27.6, 34.5, and 41.4 MPa). For each closure stress, the test was repeated three times to mitigate experimental error. Because materials and preparation can influence the constitutive properties of proppant pillars, the testing results are repeatable only if experiments use the identical preparation procedure and the same pillar size with the same type and amount of fibers and fluid glues. It should also be noted that the steel plates used to represent fracture surfaces in the experiments do not exactly mimic rock deformation. However, as will be demonstrated later in this paper, rock deformation has a considerably smaller influence on channel-fracture width and conductivity compared with proppant-pillar deformation.

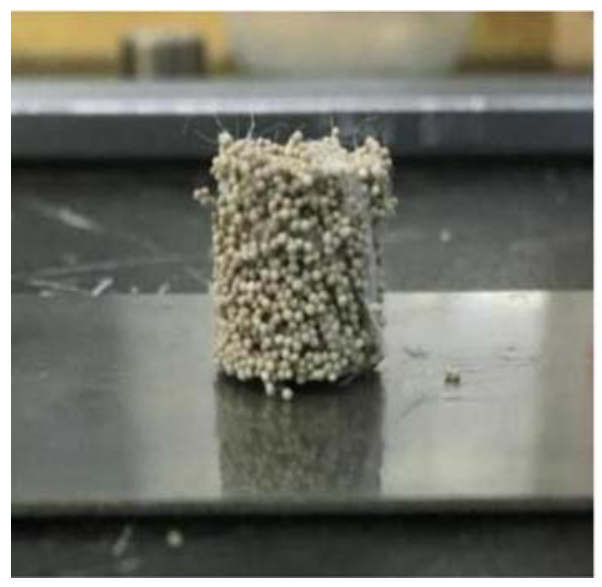

(a)

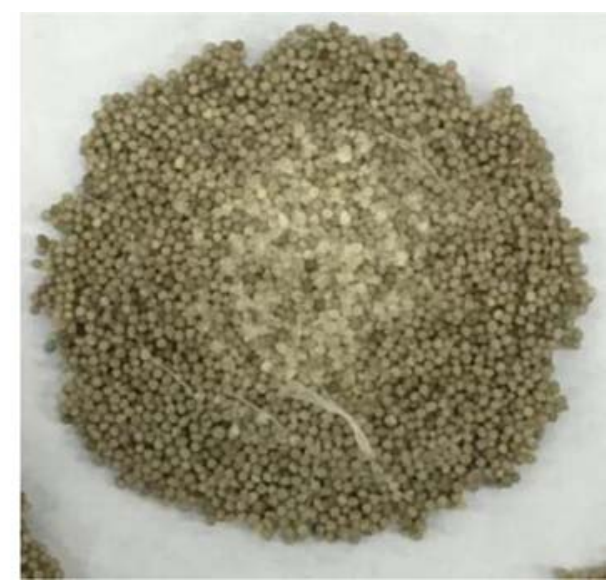

(b)

Fig. 3-Proppant pillar (a, side view) before and (b, top view) after the experiment.

Fig. 4 shows the stress/strain relationship for a single pillar. The results indicate that the proppant pillars experience significant deformation during loading. Initially, when the applied stress is very small, the strain increases rapidly. This is not surprising because packing changes and frictional resistance just starts to develop. After that, the stress increases sharply with additional strain. The reason for this phenomenological behavior might be explained as follows.

With initial contact of the loading platen (a surrogate for the fracture wall), the proppant particles in the pillars mainly rearrange their packing and fill interstitial space between the particles. As a result, a small stress can result in a large displacement when the fracture walls initially contact the proppant pack. However, as closure continues, the compaction is almost complete and proppants connect tightly with each other. For the pillar to deform at this stage, the applied stress needs to overcome the cohesive and frictional forces between proppant particles as well as normal stresses associated with frictional interaction with the rock surface. Therefore, a muchsteeper curve is observed during this period, where deformation is dramatically inhibited. After unloading, the strain has essentially no recovery (rebound). This is because the pore structure of the proppant pillar predetermines the highly compressible property of the proppant pillar and, with a strain as high as $80 \%$, the pore structure collapses, which is an irreversible phenomenon.

To incorporate the experimental results into a predictive model that will be introduced in the following sections, the characteristic deformation of a generic proppant pillar should be described mathematically. To do this, the following assumptions are made: 
1. The proppant pillars are homogeneous and composed of continuous media.

2. Loading stress is increased monotonically from zero to the maximum value.

3. There is no deformation (rebound) during unloading.

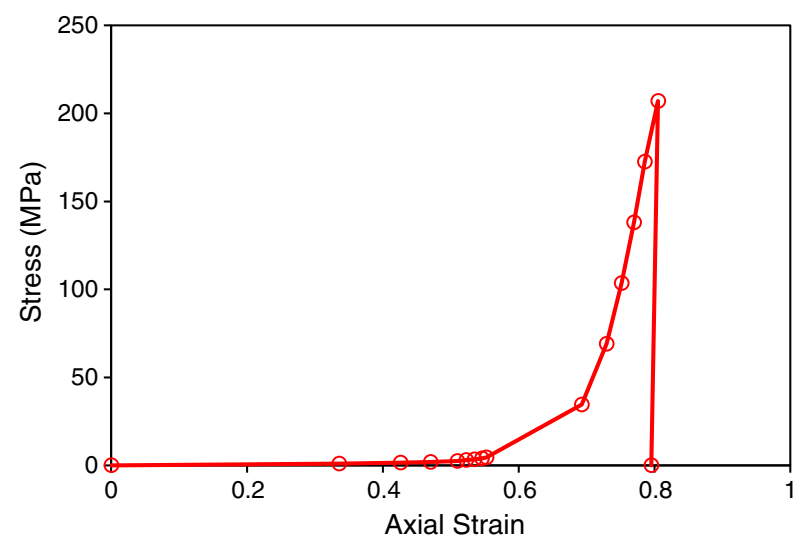

Fig. 4-Stress/axial-strain relationship of proppant pillars.

With these assumptions, a multilinear constitutive relationship was used to describe the stress/strain behavior of these proppant pillars. Table 1 listed the elastic modulus and Poisson's ratio of the proppant pillar in 14 loading intervals. The interval between any two neighboring points on the stress/strain curve can be regarded as a linear segment (i.e., the pillars exhibit linear-elastic behavior during this discrete period). Therefore, the stress/axial-strain relationship for this interval can be locally expressed as a piecewise representation for the stress/strain curves, and the stress/radial-strain relationship for the interval can also be locally expressed as a piecewise representation.

$$
\begin{aligned}
& E_{p}=\frac{\Delta \sigma}{\Delta \varepsilon}, \\
& \nu_{p}=\frac{\Delta \zeta}{\Delta \varepsilon},
\end{aligned}
$$

where $E_{p}$ is the elastic modulus of the proppant pillar (in MPa); $v_{p}$ is Poisson's ratio of the proppant pillar (dimensionless); $\Delta \sigma$ is the stress difference between two neighboring points on a stress/axial-strain curve (in MPa); $\Delta \varepsilon$ is the axial-strain difference between two neighboring points (dimensionless); and $\Delta \zeta$ is the radial-strain difference between two neighboring points (dimensionless).

\begin{tabular}{ccc} 
Stress $(\mathrm{MPa})$ & Elastic Modulus $(\mathrm{MPa})$ & Poisson's Ratio \\
\hline $0-1$ & 2.98 & 2.17 \\
$1-1.5$ & 5.52 & 2.17 \\
$1.5-2$ & 11.24 & 2.17 \\
$2-2.5$ & 12.76 & 2.17 \\
$2.5-3$ & 38.17 & 2.17 \\
$3-3.5$ & 41.67 & 2.17 \\
$3.5-4$ & 46.3 & 2.17 \\
$4-4.5$ & 73.53 & 2.3 \\
$4.5-34.5$ & 229.53 & 0.78 \\
$34.5-69$ & 942.62 & 1.11 \\
$69-103.5$ & 1554.05 & 1.06 \\
$103.5-138$ & 1885.25 & 1.05 \\
$138-172.5$ & 2197.45 & 1.07 \\
$172.5-207$ & 1760.2 & 0.75 \\
\hline
\end{tabular}

Table 1-Elastic modulus and Poisson's ratio of proppant pillar in 14 loading intervals.

By dividing the stress/axial-strain curve into $n$ segments with $P_{1}, P_{2}, \ldots, P_{n}$ as the initial stress and $\varepsilon_{1}, \varepsilon_{2}, \ldots, \varepsilon_{n}$ as the initial axial strain for each segment, elastic moduli $\left(E_{1}, E_{2}, \ldots, E_{n}\right)$ and Poisson's ratio can be obtained from Eqs. 1 and 2 . To calculate the height change and diameter change of the proppant pillars under an arbitrary closure pressure $P$, we need to determine in which segment $P$ lies (i.e., $P_{i}<P<P_{i+1}$ ), and then the change of pillar height and diameter can be obtained using

$$
h_{i}=h_{i-1}-\frac{\sigma_{i}-\sigma_{i-1}}{E_{p}} \times h_{0},
$$




$$
d_{i}=d_{i-1}+\frac{\nu_{p}\left(\sigma_{i}-\sigma_{i-1}\right)}{E_{p}} \times d_{0}
$$

where $h_{i}$ is the top height of segment $i$ of the proppant pillar (in mm); $h_{i-1}$ is the top height of segment $i-1$ of the proppant pillar (in $\mathrm{mm}) ; h_{0}$ is the initial height of the proppant pillar (in $\mathrm{mm}$ ); $d_{i}$ is the diameter of segment $i$ of the proppant pillar (in mm); $d_{i-1}$ is the diameter of segment $i-1$ of the proppant pillar (in mm); $d_{0}$ is the initial diameter of the proppant pillar (in mm); $\sigma_{i}$ is the final stress of segment $i$ (in $\mathrm{MPa}$ ); $\sigma_{i-1}$ is the final stress of segment $i-1$ (in $\mathrm{MPa}$ ); $E_{p}$ is the deformation modulus of segment $i$ (in MPa); and $v_{p}$ is the Poisson's ratio of segment $i$ (dimensionless).

Using Eqs. 3 and 4, Fig. 5 shows the evolution of pillar height and diameter at different closure stresses in the analytical model and the experiment.

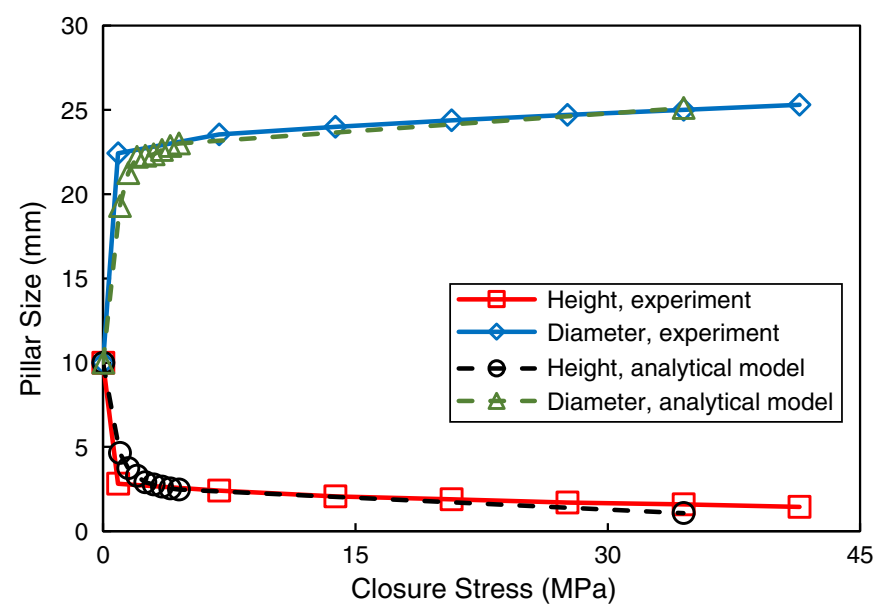

Fig. 5-Evolution of proppant-pillar height and diameter at different closure stresses in the analytical model and the experiment.

Deformation of the Fracture Surface. Because of nonuniform stress distribution on the fracture surface, the fracture surface will have uneven deformation. This subsection develops an analytical solution for the fracture-width change induced by the fracturesurface deformation.

According to the theory of elasticity, the vertical deformation (subsidence) $\omega$, at an arbitrary point $M$ on a semi-infinite body under a normally distributed stress, can be determined by (Johnson 1985)

$$
\omega=\frac{\left(1-\nu_{r}^{2}\right) \sigma}{\pi E_{r}} \iint \mathrm{d} s \mathrm{~d} \psi
$$

where $\omega$ is the vertical deformation (in mm); $v_{r}$ is the Poisson's ratio of rock (dimensionless); $E_{r}$ is the elastic modulus of rock (in $\mathrm{MPa}$ ); $\sigma$ is the surface loading (in $\mathrm{MPa}$ ); and $\psi$ and $s$ are geometric parameters related to the relative location between the investigated point $M$ and the loading area, as shown in Figs. 6 and 7.

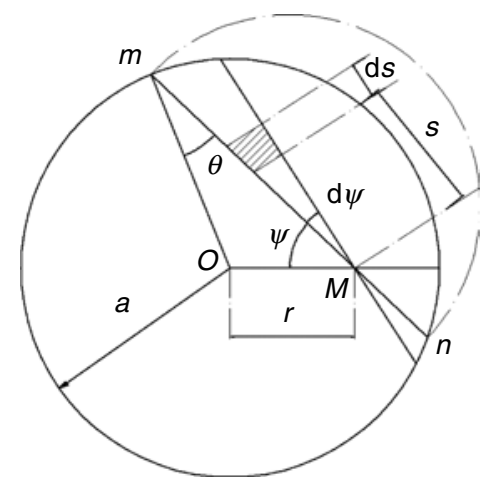

Fig. 6-An arbitrary point $M$ within the loading area.

Overall Subsidence (Deformation in the Loading Area). In Fig. 6, point $O$ is the center of the projected circle of the proppant pillar. The diameter of the projected circle is $r$, and the loading force on the circle area is $\sigma$. Point $M$ is in the projected circle. According to Eq. 5, the subsidence of point $M$ can be rewritten as

$$
\alpha=\frac{4\left(1-\nu_{r}^{2}\right) \sigma r}{\pi E_{r}} \int_{0}^{\frac{\pi}{2}} \sqrt{1-\frac{c^{2}}{r^{2}} \sin ^{2} \psi} \mathrm{d} \psi .
$$




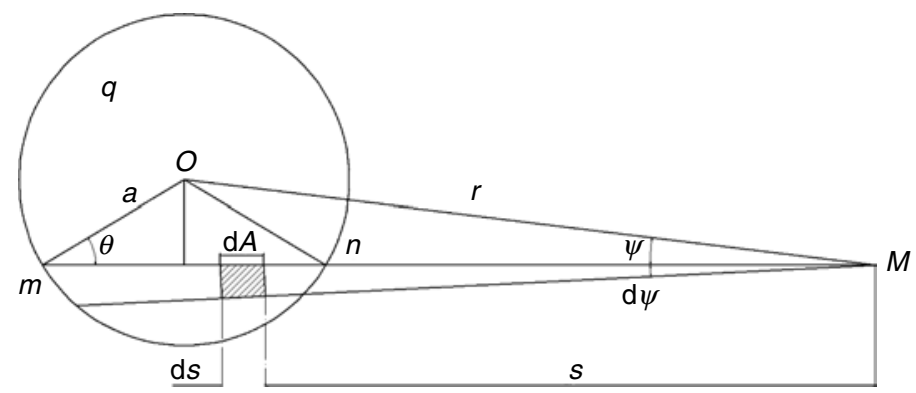

Fig. 7-An arbitrary point $M$ outside the loading area.

The average subsidence $\alpha$ of the pillar can be determined using the area-weighted method,

$\alpha=\frac{4\left(1-\nu_{r}^{2}\right) \sigma}{\pi^{2} E_{r} r} \iint_{D}\left(\int_{0}^{\frac{\pi}{2}} \sqrt{1-\frac{c^{2}}{r^{2}} \sin ^{2} \psi} \mathrm{d} \psi\right) c \mathrm{~d} c \mathrm{~d} \theta$.

Using Simpson's rule, Eq. 7 can be approximated as

$\alpha=\frac{1.3\left(1-\nu_{r}^{2}\right) \sigma r}{E_{r}}$,

where $r$ is the radius of the circular loading area, or the pillar radius in this paper (in mm).

Subsidence in Unloaded Area (Deformation Outside the Loaded Area). As shown in Fig. 7, point $O$ is the center of the projected circle of the proppant pillar. The diameter of the projected circle is $r$, and the loading force on the circle area is $\sigma$. Point $M$ is at the outside of the projected circle. According to Eq. 5, the subsidence of point $M$ can be expressed as

$$
\beta=\frac{4\left(1-\nu_{r}^{2}\right) \sigma c}{\pi E_{r}}\left[\int_{0}^{\frac{\pi}{2}} \sqrt{1-\frac{r^{2}}{c^{2}} \sin ^{2} \theta} \mathrm{d} \theta-\left(1-\frac{r^{2}}{c^{2}}\right) \int_{0}^{\frac{\pi}{2}} \frac{\mathrm{d} \theta}{\sqrt{1-\frac{r^{2}}{c^{2}} \sin ^{2} \theta}}\right] .
$$

When there are multiple pillars, the subsidence at point $M$ can be obtained using the superposition principle,

$$
\beta=\sum_{i=1}^{m} \frac{4\left(1-\nu_{r}^{2}\right) \sigma c_{i}}{\pi E_{r}}\left[\int_{0}^{\frac{\pi}{2}} \sqrt{1-\frac{r^{2}}{c_{i}^{2}} \sin ^{2} \theta} \mathrm{d} \theta-\left(1-\frac{r^{2}}{c_{i}^{2}}\right) \int_{0}^{\frac{\pi}{2}} \frac{\mathrm{d} \theta}{\sqrt{1-\frac{r^{2}}{c_{i}^{2}} \sin ^{2} \theta}}\right]
$$

Eq. 10 can be simplified using Simpson's rule as

$$
\beta=\sum_{i=1}^{m} \frac{\left(1-\nu_{r}^{2}\right) \sigma c_{i}}{3 E_{r}}\left[\left(1+4 \sqrt{1-\frac{r^{2}}{2 c_{i}^{2}}}+\sqrt{1-\frac{r^{2}}{c_{i}^{2}}}\right)-\left(1-\frac{r^{2}}{c_{i}^{2}}\right)\left(1+\frac{4}{\sqrt{1-\frac{r^{2}}{2 c_{i}^{2}}}}+\frac{1}{\sqrt{1-\frac{r^{2}}{c_{i}^{2}}}}\right)\right],
$$

where $c_{\mathrm{i}}$ is the distance between point $M$ and the center of pillar $i$ (in $\mathrm{mm}$ ).

As shown in Fig. 8, the subsidence $(\alpha)$ of the proppant pillar represents the reduction of the overall fracture width caused by the fracture-surface displacement, while the subsidence $(\beta)$ in the region beyond the actual loading area represents the interfering deformation caused by the support of the pillar. The difference $(\delta)$ between the two is the actual reduction in fracture width caused by subsidence. Because the total fracture-width change $\left(\delta_{1}\right)$ caused by surface displacement is the sum of fracture-width change $\delta$ on both the top and bottom plates, $\delta_{1}$ can be expressed as

$$
\delta_{1}=2 \delta=2 \alpha-2 \beta,
$$

where $\delta_{1}$ is the total fracture-width change caused by fracture-surface displacement (in mm); $\delta$ is the change of fracture width at the calculation point (in $\mathrm{mm}$ ); $\alpha$ is overall subsidence of the proppant pillar (in $\mathrm{mm}$ ); and $\beta$ is the deformation outside the loading area (in mm).

Proppant Embedment of the Pillars. Li et al. (2015b) and Gao et al. (2013) presented detailed studies on proppant embedment. In this paper, we adopted the $\mathrm{Li}$ et al. (2015b) model for calculating proppant embedment. The model was initially developed for conventionally propped fractures. However, for channel fractures, proppant embedment shares the same physics because only the layer of proppants contacting the fracture surface might have embedment. According to Li et al. (2015b), the change of distance between the centers of two spherical proppants under an external force $P$ meets the relationship

$$
a=\frac{\frac{3}{4} P C_{E}}{\left(\frac{3}{4} P C_{E} \frac{R_{1} R_{2}}{R_{1}+R_{2}}\right)^{\frac{1}{3}}},
$$


where $a$ is the change of distance between the centers of two spheres, $P$ is the external force applied on two spheres, and $R_{1}$ and $R_{2}$ are the radii of two spheres. $C_{E}$ is expressed as

$$
C_{E}=\frac{1-v_{1}^{2}}{E_{1}}+\frac{1-v_{2}^{2}}{E_{2}},
$$

where $v_{1}$ and $v_{2}$ are the Poisson's ratio of two spheres and $E_{1}$ and $E_{2}$ are the elastic moduli of two spheres.

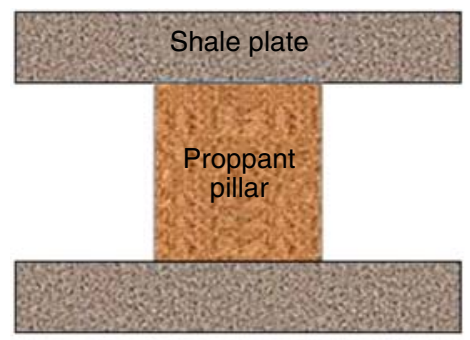

(a)

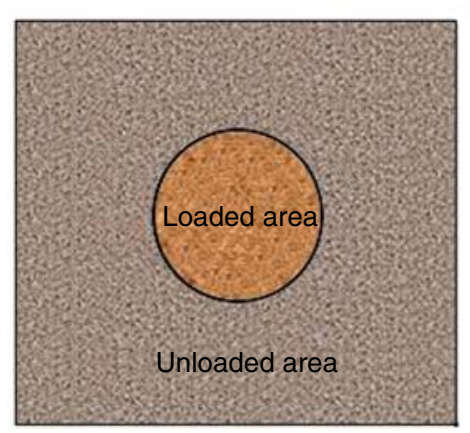

(c)

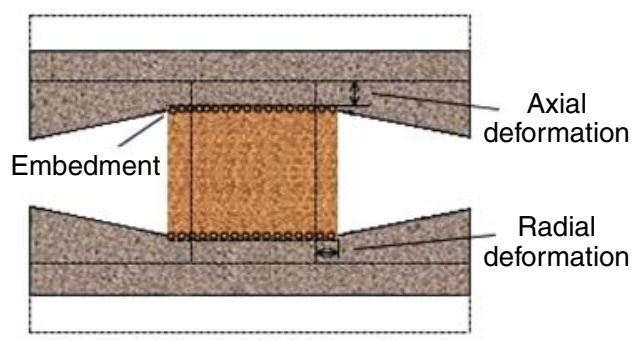

(b)

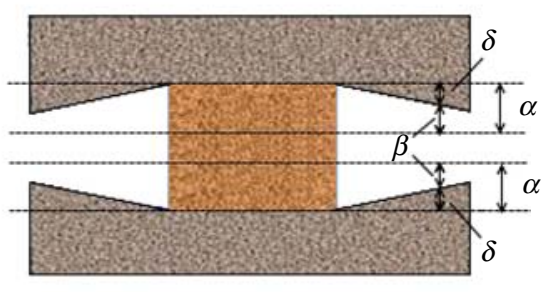

$\delta=\alpha-\beta$

(d)

Fig. 8-Schematic of deformation of proppant pillar and fracture. (a) Original geometries of the proppant pillar and the shale plate before fracture closing. (b) Deformed proppant pillar and the shale plate under closing stress. (c) Loading area of the proppant pillar. (d) Uneven deformation of the fracture.

As $R_{2} \rightarrow \infty$, the surface of Sphere 2 becomes a plane. $a$ becomes $a_{1}$, which means the change of distance between the center of a sphere and the surface of a plane, in Eq. 15. $a_{1}$ consists of the deformation of Sphere 1 and the embedment in the plane,

$$
a_{1}=\frac{2\left(\frac{3}{8} P D_{1} C_{E}\right)^{\frac{2}{3}}}{D_{1}}
$$

where $D_{1}$ is the diameter of Sphere 1 .

Furthermore, if $E_{2} \rightarrow \infty$, the plane becomes rigid. $a_{1}$ is expressed as $a_{2}$, or the deformation of Sphere 1 when it meets a rigid plane,

$$
a_{2}=\frac{2\left(\frac{3}{8} P D_{1} \frac{1-v_{1}^{2}}{E_{1}}\right)^{\frac{2}{3}}}{D_{1}} .
$$

Combining Eqs. 15 and 16, the embedment of Sphere 1 in the plane $\delta_{2}$ can be calculated by

$$
\delta_{2}=a_{1}-a_{2}=\frac{2\left(\frac{3}{8} P D_{1}\right)^{\frac{2}{3}}}{D_{1}}\left[\left(\frac{1-v_{1}^{2}}{E_{1}}+\frac{1-v_{2}^{2}}{E_{2}}\right)^{\frac{2}{3}}-\left(\frac{1-v_{1}^{2}}{E_{1}}\right)^{\frac{2}{3}}\right] .
$$

Now, we use Eq. 18 to establish the relationship between the external force on Sphere 1 and the closing stress,

$$
P=p\left(K D_{1}\right)^{2}
$$

Combining Eqs. 17 and 18 and substituting the elastic parameters of rock and proppant particles, the proppant embedment $\delta_{2}$ meets

$$
\delta_{2}=\frac{2\left(\frac{3}{8} p K^{2} D_{1}^{3}\right)^{\frac{2}{3}}}{D_{1}}\left[\left(\frac{1-v_{p r}^{2}}{E_{p r}}+\frac{1-v_{r}^{2}}{E_{r}}\right)^{\frac{2}{3}}-\left(\frac{1-v_{p r}^{2}}{E_{p r}}\right)^{\frac{2}{3}}\right],
$$


where $\delta_{2}$ is the embedment of the proppants, $K$ is a distance coefficient, $v_{p r}$ is the Poisson's ratio of proppants, and $E_{p r}$ is the elastic modulus of proppants.

Fracture Width and Conductivity. Fracture width is controlled by the deformation and embedment of the proppant pillars. For an arbitrary location in the fracture, the width can be expressed as

$$
w=h_{0}-\Delta h-\delta_{1}-\delta_{2}
$$

where $w$ is the fracture width (in $\mathrm{mm}$ ) and $\Delta h$ is the height change of the proppant pillars (in mm).

In this study, the proppant pillars are assumed to be arranged in an ordered square pattern. The representative square unit shown in Fig. 9 is used in the calculations. The black regions (Fig. 9b) at the corners represent the pillar locations, and the white region is the open channel.

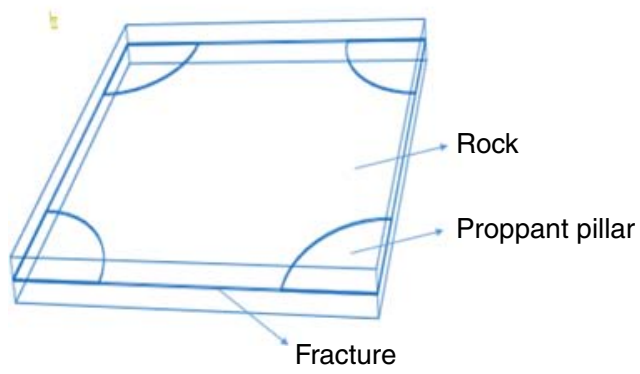

(a) 3D view

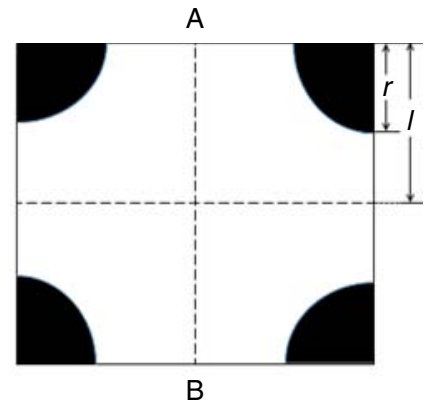

(b) 2D view

Fig. 9-Layout of proppant pillars in a fracture.

The volume of a single proppant pillar can be then approximated as (Zheng et al. 2017)

$$
V_{p}=\frac{Q t \rho_{f}}{N \eta \rho_{p}} .
$$

The radius of the proppant pillar is

$$
r=\sqrt{\frac{Q t \rho_{f}}{N \eta \rho_{p} w \pi}},
$$

where $Q$ is the flow rate (in $\mathrm{m}^{3} / \mathrm{s}$ ); $t$ is the pulse-periodic time [the pumping proppant-laden fluid (PLF) and proppant-free fluid (PFF) are the same] (in seconds); $\rho_{f}$ is the density of proppant-laden fluid (in $\mathrm{kg} / \mathrm{m}^{3}$ ); $\rho_{p}$ is the density of the proppant pillar (in $\mathrm{kg} / \mathrm{m}^{3}$ ); $N$ is the number of total perforations (dimensionless); and $\eta$ is the effective ratio of perforations (dimensionless).

There are two different conductive media within channel fractures: porous proppant pillars and free channels. Most fluid flows through the free channels with minimal (or at least reduced) resistance, but fluid also flows through pores in the proppant pillars. Therefore, fluid flow in the fracture can be described using a dual-medium model. The flow in the proppant pillars is modeled using Darcy's law or a similar approximation, while the flow in the free channels is described using more-fundamental fluid-mechanics concepts (Zhu et al. 2016).

In particular, considering the proppant pillars as a porous medium, we approximate their permeability using the Kozeny-Carman model (Bear 1972),

$$
k_{p}=\frac{\phi^{3}}{36 C(1-\phi)^{2}}(2 R)^{2},
$$

where $k_{p}$ is the permeability of the proppant pillar (in $\mathrm{mm}^{2}$ ); $\phi$ is the porosity of the proppant pillar (dimensionless); $R$ is the radius of the proppant particles (in $\mathrm{mm}$ ); and $C$ is the Kozeny-Carman constant (dimensionless). This constant $C$ is equal to approximately 5 for uniform spherical particles.

The porosity $\phi$ of the proppant pillars in Eq. 23 is very difficult to measure experimentally, although it can be approximated using assumptions on initial packing and the strain relationships. It can be readily estimated with

$$
\phi=\frac{V_{p}-m_{p} / \rho_{p r}}{V_{p}},
$$

where $V_{p}$ is the volume of the proppant pillar (in $\mathrm{m}^{3}$ ); $\rho_{p r}$ is the density of the proppant particles (in $\mathrm{kg} / \mathrm{m}^{3}$ ); and $m_{p}$ is the mass of the proppant pillar (in $\mathrm{kg}$ ). Because the height and the diameter of the proppant pillar during deformation can be piecewise approximated using the methods described previously, the volume of the proppant pillar can be estimated. The density of proppant particles in this study is $2650 \mathrm{~kg} / \mathrm{m}^{3}$, and the pillar mass in Eq. 24 can be measured readily.

The fluid flow in open channels can be described using a 1D application of the Navier-Stokes equations (Asgian et al. 1995; Bolintineanu et al. 2017; Zheng et al. 2017). The permeability of the channels can be determined using the classic cubic law (lubrication theory), 


$$
k_{c}=\frac{w^{2}}{12}
$$

where $k_{c}$ is the effective permeability of the channel (in $\mathrm{mm}^{2}$ ).

Using the geometry in Fig. 10 (right-hand panel) as a calculation unit and assuming fluid flows from the left side to the right side of the unit, the flow rate through the unit in Fig. 10 can be expressed by

$$
Q=-\frac{k A}{\mu} \frac{\mathrm{d} p}{\mathrm{~d} x},
$$

where $\mu$ is the dynamic viscosity of fluid (in $\mathrm{Pa} \cdot \mathrm{s}$ ) and $A$ is the cross-sectional flow area (in $\mathrm{m}^{2}$ ).

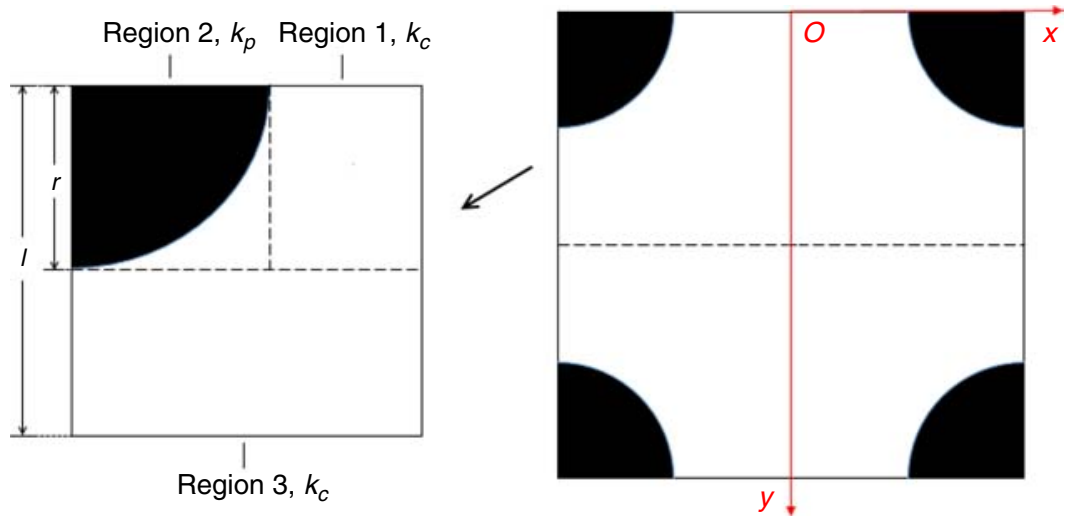

Fig. 10-Calculation model for fracture conductivity.

As indicated, fluid is specified to flow from left to right in Fig. 10. Thus, in Fig 10 (left), Regions 1 and 2 have the same flow rate, and the total pressure loss across the unit is equal to the sum of the pressure drops across Regions 1 and 2. Therefore, the equivalent permeability of Regions 1 and 2 can be obtained according to the differential-pressure-superposition principle (Guo et al. 2017),

$$
\frac{1}{k_{\mathrm{eq}}^{\prime}}=\frac{1}{k_{p}}(1-\gamma)+\frac{1}{k_{c}} \gamma,
$$

where $k_{\mathrm{eq}}^{\prime}$ is the equivalent permeability for Regions 1 and 2 (in $\mathrm{mm}^{2}$ ) and $\gamma$ is the ratio of pillar radius to fracture-unit length (dimensionless).

The total flow rate across the unit is equal to the sum of the flow rates across Region 1 (or Region 2) and Region 3 . Therefore, the equivalent permeability of Regions 1, 2, and 3 can be obtained according to the flow-superposition principle,

$$
k_{\mathrm{eq}}=k_{\mathrm{eq}}^{\prime} \gamma+k_{c}(1-\gamma)
$$

where $k_{\text {eq }}$ is the equivalent permeability for Regions 1,2 , and 3 (in $\mathrm{mm}^{2}$ ).

Finally, the conductivity of a channel fracture can be determined as

$$
F=k_{\mathrm{eq}} w
$$

where $F$ is the fracture conductivity. During fracture closure, the stress applied on the fracture surfaces is not uniform. This results in a nonuniform fracture aperture. It is worth noting that in reality, fluid can skirt proppant pillars, a phenomenon that is not considered in the 1D flow assumption in Fig. 10. Significant future efforts are required to incorporate this phenomenon into the channel-fracturing model to improve its accuracy, which is beyond the scope of the current paper.

Gillard et al. (2010) have demonstrated theoretically and experimentally that the conductivity of a channel fracture can be 1.5 to 2.5 orders of magnitude higher than that of a conventional fracture. This implies that the channel network between proppant pillars in a channel fracture dominates fracture conductivity.

As mentioned previously, if the distance between pillars is too small, some neighboring pillars might contact or overlap with each other after deformation. Under those conditions, high-conductivity channels will disappear and the conductivity of the fracture reduces to that of a conventional hydraulic fracture. On the other hand, if the distance between proppant pillars is too large, the fracture might close because of insufficient support, resulting in the failure of a channel-fracturing treatment. To simplify the analysis, this paper focuses only on conditions with effective channels between proppant pillars.

Model Validation. The proposed conductivity model was verified experimentally. The proppant tested in the laboratory comprises $92 \%$ quartz, $5 \%$ feldspar, $1 \%$ albite, and $2 \%$ calcite. The proppant was well-blended with $4 \%$ fibers and proppant and fibers were glued together. The samples were then put into a custom-designed metal mold and heated at $60^{\circ} \mathrm{C}$ for 1 hour to form the proppant pillars. 10 pillars were made with a diameter of $0.01 \mathrm{~m}$ and a height of $0.01 \mathrm{~m}$. The pillars were placed in the conductivity-measurement chamber in a square-layout pattern, as shown in Fig. 11.

The steel plate was used to perform the channel-fracturing experiment to verify the established fracture-conductivity model. The steel plate is $0.14 \mathrm{~m}$ in length and $0.038 \mathrm{~m}$ in width. An FCES-100 fracture-conductivity-test system was used to measure the conductivity of the fracture with proppant pillars at progressively increasing closure pressures of 0.5, 2, 10, 30, and $50 \mathrm{MPa}$ (Zhang et al. 2017). 


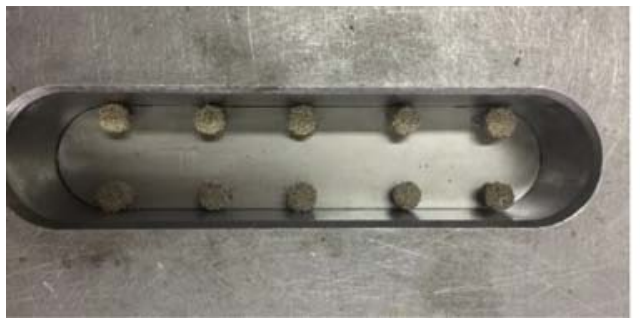

(a) Proppant pillar in the experimental cell

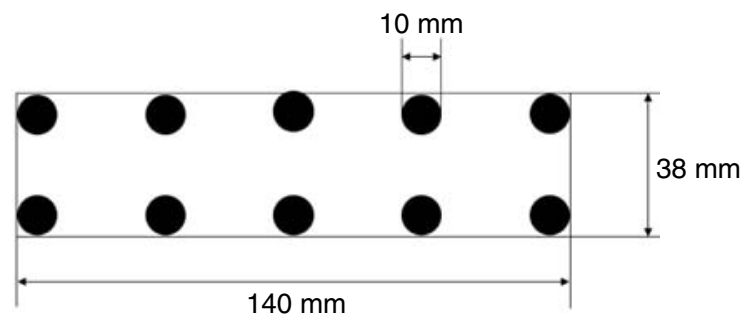

(b) Proppant-pillar layout in the fractureconductivity model

Fig. 11-Layout of proppant pillars in the validation experiment and in the model.

The distribution of fracture width during the experiment is difficult to measure. Hence, the measured fracture conductivity was used to verify the model. The placement of proppant pillars in the fracture-conductivity model is shown Fig. 11b, consistent with that in the experiment (Fig. 11a). Fig. 12 compares the fracture conductivity calculated from the model and measured from the experiments at different closure stresses. The predictions and the measurements agree reasonably well with each other, verifying the utility of the proposed model.

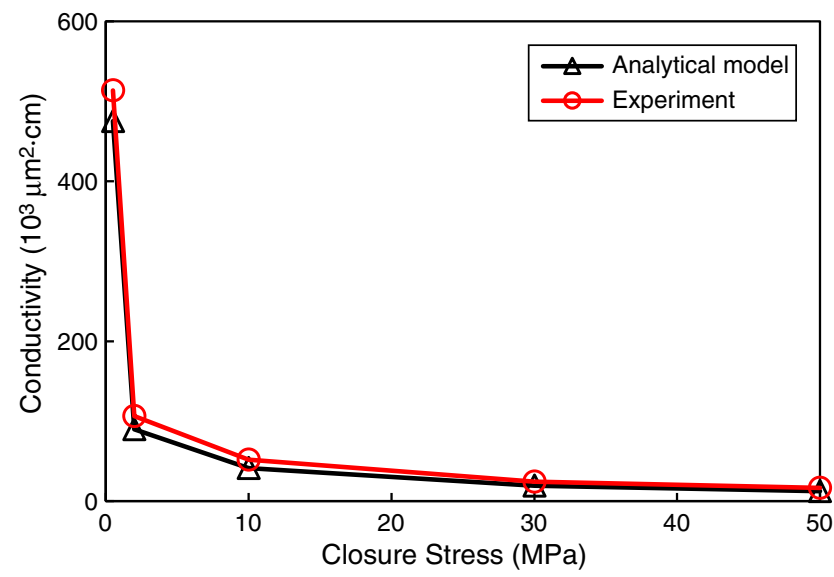

Fig. 12-Comparison of fracture conductivity measured in the experiment and predicted by the proposed model.

\section{Parameter-Sensitivity Analysis}

Recognizing its utility, the model described in the previous section is used to predict fracture-width distribution and fracture conductivity as a function of various relevant treatment and formation variables. The Shahejie Formation in Well X27 in Shenli Oil Field was used as an example for the application of channel fracturing. The depth of the formation is 3050 to $3500 \mathrm{~m}$. The closure stress is approximately $50 \mathrm{MPa}$. The Young's modulus and Poisson's ratio of the target formation are $30 \mathrm{GPa}$ and 0.28 , respectively. The fracture width varies between 5 and $10 \mathrm{~mm}$ according to the calculation results of the FRACPRO-PT software (Cleary 1994; Zhu et al. 2015). For simplicity, the fracture width is assumed to be $5 \mathrm{~mm}$. In the channel-fracturing treatment, the total injection time is $75 \mathrm{minutes}$. The pump rate is $5 \mathrm{~m}^{3} / \mathrm{min}$. The pulse time for proppant-laden and proppant-free periods is 1 minute. The densities of the PFF and PLF are 500 and $2650 \mathrm{~kg} / \mathrm{m}^{3}$, respectively. There were 72 perforations used, with an effective-perforation ratio of $80 \%$, which means only approximately $80 \%$ of perforations are broken by the fracturing fluid. The diameter of the proppant pillars is approximated to be $1 \mathrm{~m}$ using these data and Eq. 20. All the parameters required for the simulations are summarized in Table 2.

\begin{tabular}{lc} 
Parameters & Values \\
\hline Diameter of proppant pillars & $1 \mathrm{~m}$ \\
Height of proppant pillars & $0.005 \mathrm{~m}$ \\
Young's modulus of proppant pillars & Refer to Fig. 5 \\
Poisson's ratio of proppant pillars & Refer to Fig. 5 \\
Closure stress & $50 \mathrm{MPa}$ \\
Young's modulus of formation & $30 \mathrm{GPa}$ \\
Poisson's ratio of formation & 0.28 \\
\hline
\end{tabular}

Table 2-Parameters required for simulations. 
Influence of Closure Stress on Fracture Width and Fracture Conductivity. In this subsection, simulation results are presented to illustrate the influence of closure stress on fracture width and conductivity in a channel-fracturing scenario. We note again here that our definition for "fracture width" is actually the fracture width of the open channel. The pillar distance is 2 m. Fracture behavior under closure stresses of $0.5,2,10,30$, and $50 \mathrm{MPa}$ was investigated. Note that for simplification, the deformation of a proppant pillar and the stress applied on it are assumed to be uniform. In reality, the stress on the outer portion of the proppant pillar could be larger than that on the inner portion; as a result, larger deformation of the proppant pillar will occur near the pillar circumference, whereas smaller deformation will be at the center of the pillar (Wang and Elsworth 2018).

Fig. 13 shows the fracture-width distribution at the different closure stresses. In Fig. 13, the red areas at the corners are the locations of proppant pillars. The calculations indicate that, as expected, fracture width generally decreases with an increase of closure stress, and that the locations farther from the pillars experience smaller fracture width at this location, again as expected.

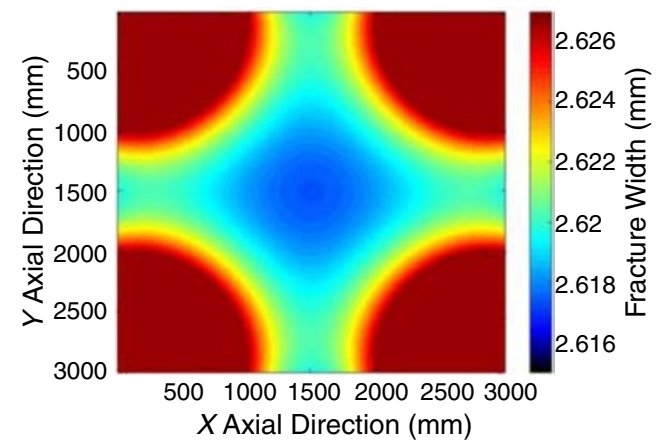

(a) Closure stress $=2 \mathrm{MPa}$

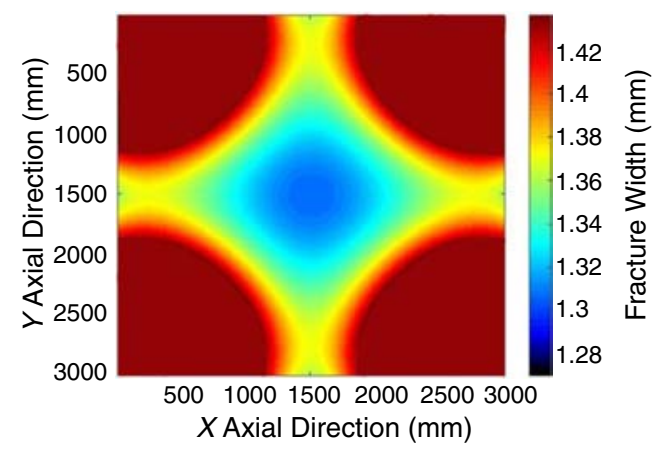

(c) Closure stress $=30 \mathrm{MPa}$

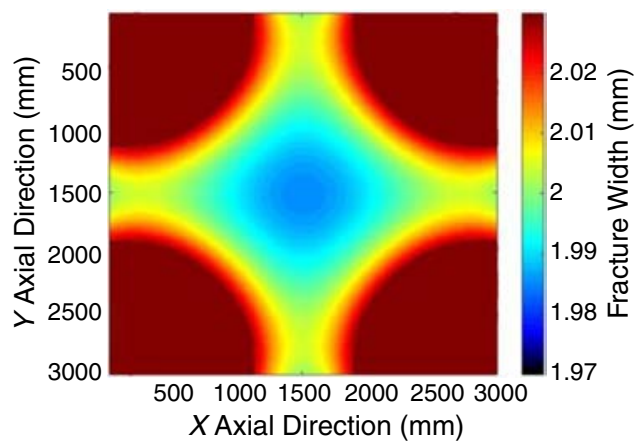

(b) Closure stress $=10 \mathrm{MPa}$

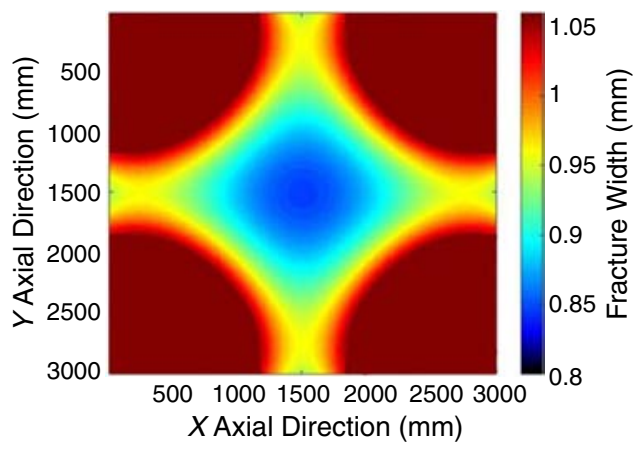

(d) Closure stress $=50 \mathrm{MPa}$

Fig. 13-Fracture-width distribution under different closure stresses in channel fracturing (red areas at the corners are the locations of the pillars). The original fracture width was set as $5 \mathrm{~mm}$. (a) Closure stress = $2 \mathrm{MPa}$; (b) closure stress = $10 \mathrm{MPa}$; (c) closure stress $=30 \mathrm{MPa}$; (d) closure stress $=50 \mathrm{MPa}$.

Fig. 14 plots the fracture-width distribution along the $y$-axis, which overlaps with Line AB in Fig. 9. Again, the simulations show that the fracture width is smaller at locations farther away from the pillars. Because the center of the model is farthest from the pillars, it has the smallest fracture width. The rate of change in fracture width decreases with increasing closure stress. When the closure stress increases from 0.5 to $2 \mathrm{MPa}$, the fracture experiences an initial, dramatic width reduction of $1.5 \mathrm{~mm}$, whereas with closure stress changing from 10 to $50 \mathrm{MPa}$, the pillar has significantly stiffened and the fracture-width reduction is only approximately $1 \mathrm{~mm}$.

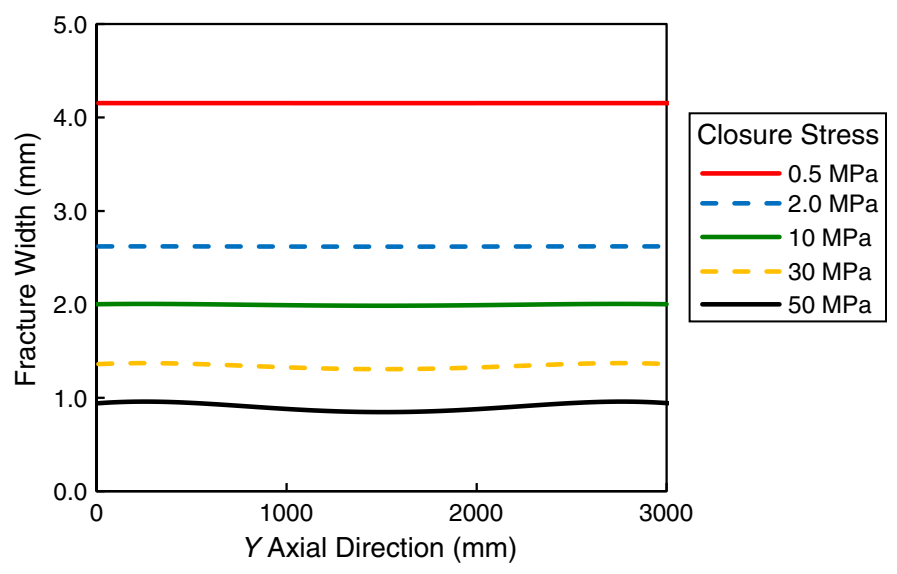

Fig. 14-Fracture width along the center Line $A B$ (as shown in Fig. 9b) under different closure stresses. Note that the "closure stress $=50 \mathrm{MPa}$ " curve is the same as the "Young's moduli $=30 \mathrm{GPa}$ " curve in Fig. 17. 
Fig. 15 shows the fracture volume (the volume within the hydraulic fracture) and conductivity for different closure stresses. Both of these concurrently decrease with an increase in the closure stress. When the closure stress is relatively small, the fracture exhibits relatively strong stress sensitivity. The stress dependency of fracture width decreases when the closure stress exceeds 2 MPa. When the closure stress reaches $50 \mathrm{MPa}$, the fracture still has a conductivity of 2520 darcy $\cdot \mathrm{cm}$, which is considerably higher compared with that of conventional hydraulic fractures with uniform proppant distribution.

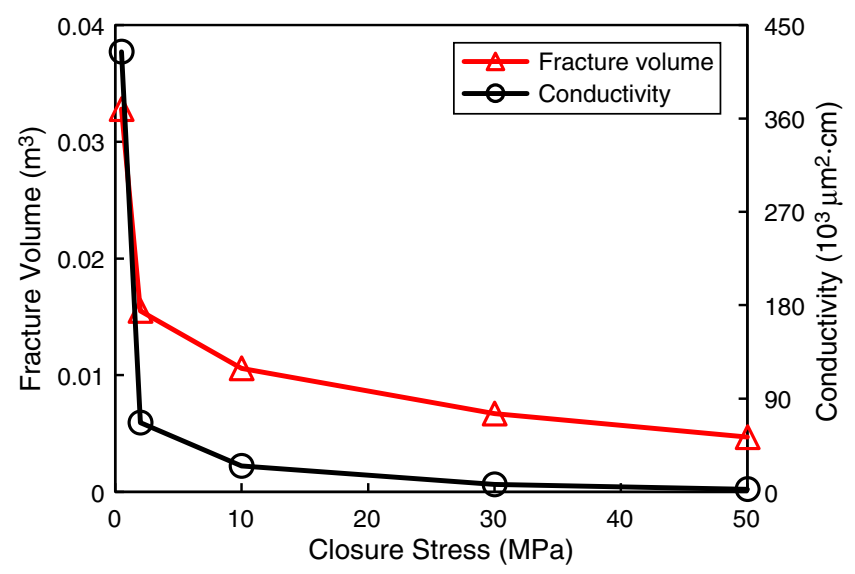

Fig. 15-Fracture volume and conductivity for different closure stresses.

Influence of Young's Modulus on Fracture Width and Fracture Conductivity. The next set of numerical experiments investigates the effect of the formation's Young's modulus on fracture width and conductivity. The closure stress and pillar distance are kept constant at $50 \mathrm{MPa}$ and $2 \mathrm{~m}$, respectively. Poisson's ratio of the formation is prescribed to be 0.28 .

Fig. 16 shows the distribution of fracture width with different formation Young's moduli. The simulation results indicate that, with the increase of formation Young's modulus, the fracture width increases. The fracture-width change away from the pillars is also restricted. This is because a larger formation Young's modulus restricts the deformation of proppant pillars.

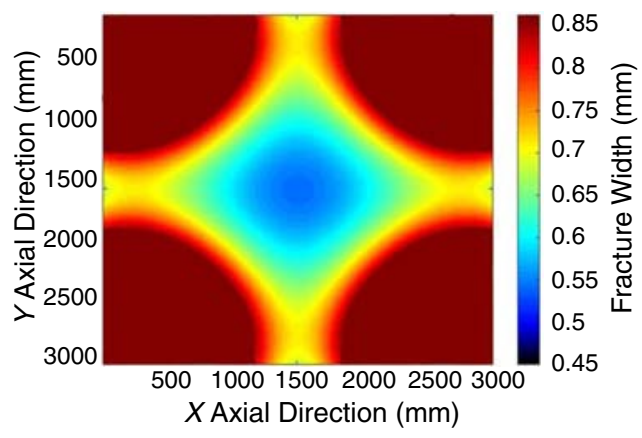

(a) Rock modulus $=20 \mathrm{GPa}$

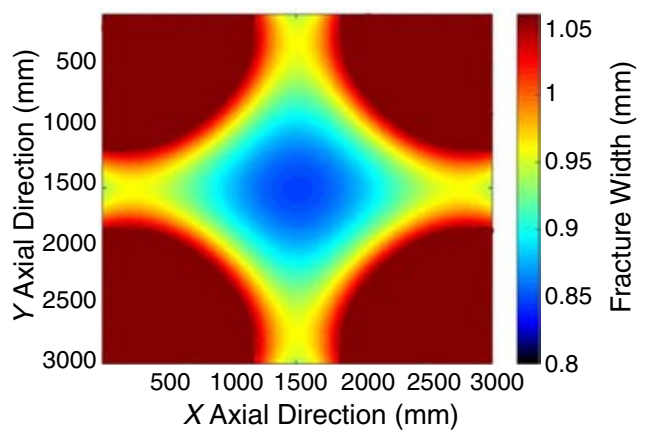

(c) Rock modulus $=30 \mathrm{GPa}$

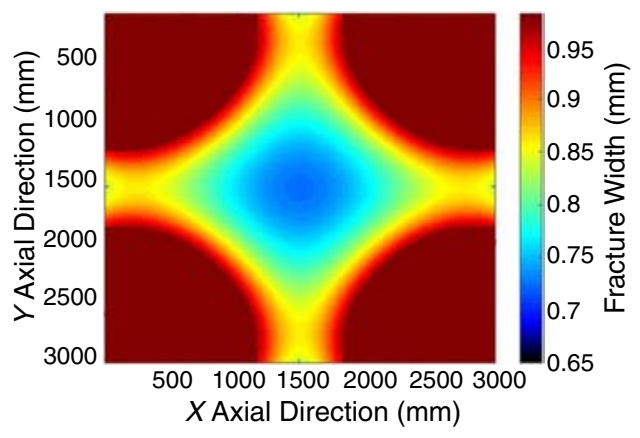

(b) Rock modulus $=25 \mathrm{GPa}$

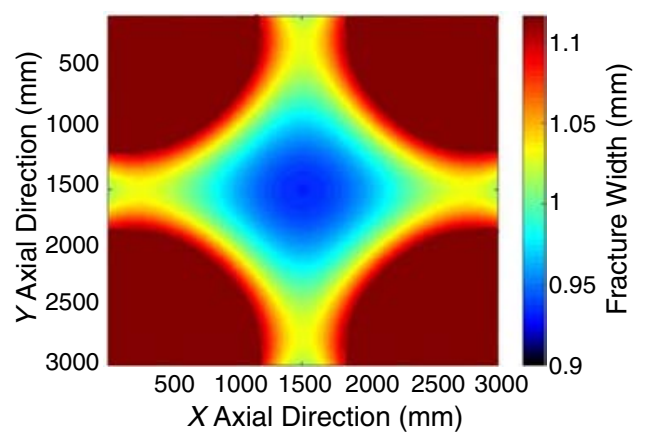

(d) Rock modulus $=35 \mathrm{GPa}$

Fig. 16-Fracture width with different formation Young's moduli. (a) Rock modulus $=20 \mathrm{GPa}$; (b) rock modulus $=25 \mathrm{GPa}$; (c) rock modulus $=30 \mathrm{GPa}$; (d) rock modulus $=35 \mathrm{GPa}$.

Fig. 17 displays the fracture width along the center Line AB, as shown in Fig. 9b. The simulations demonstrate that with the increase of formation modulus, the average width of the fracture increases. However, the rate of width change decreases. In addition, the smaller the value of Young's modulus, the less uniform is the fracture-width distribution. In Fig. 17, the "Young's modulus = 30 GPa" curve in black is the same as the "closure stress $=50 \mathrm{MPa}$ " curve in Fig. 14. 


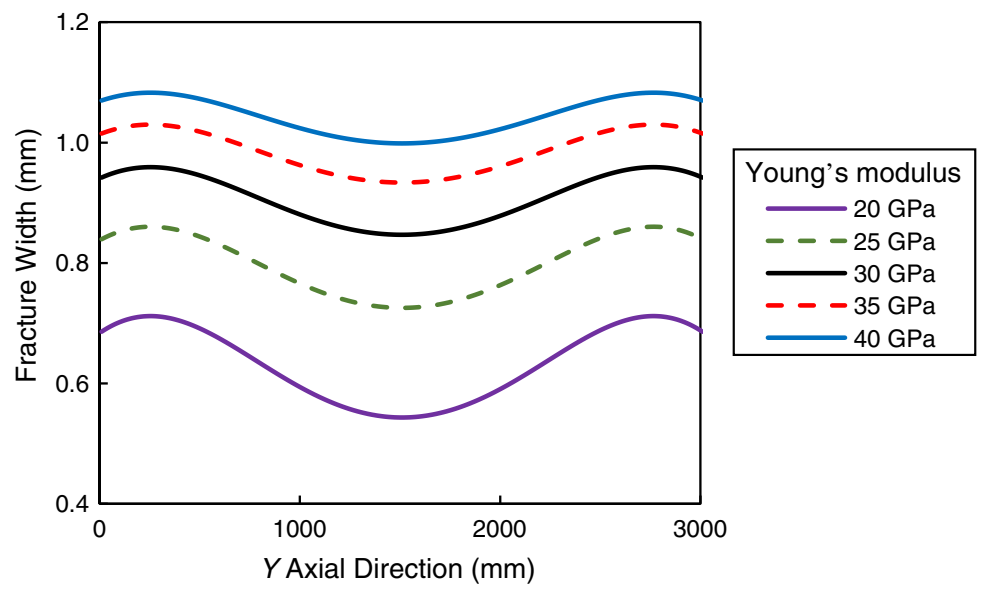

Fig. 17-Fracture width along the center Line AB (as shown in Fig. 9b) with different rock Young's moduli. Note that the "Young's modulus = 30 GPa" curve is the same as the "closure stress = 50 MPa" curve in Fig. 14.

The influences of rock modulus on fracture volume and conductivity are shown in Fig. 18. Both volume and conductivity increase with an increase of Young's modulus. The change of fracture volume is relatively small with Young's modulus, whereas the change of conductivity is relatively large. This dichotomy implies that fracture conductivity not only is related to fracture volume but also is a fairly strong function of fracture-width distribution.

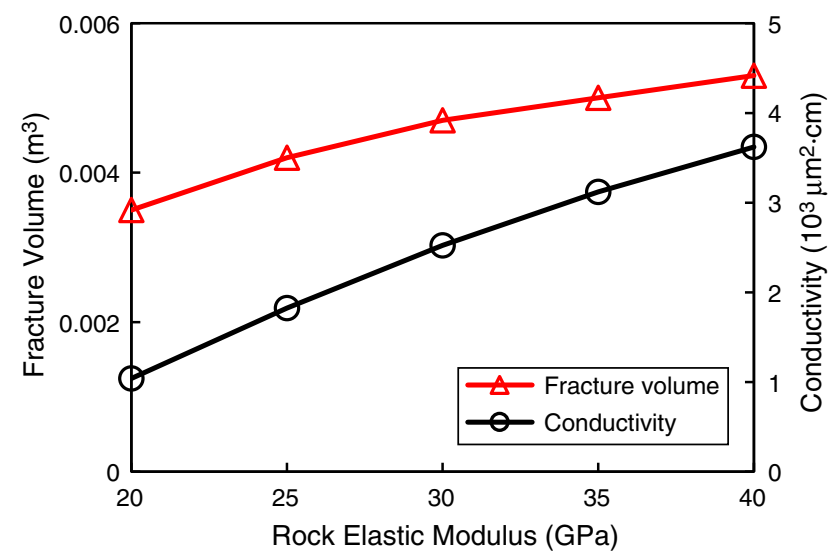

Fig. 18-Fracture volume and conductivity with different rock Young's moduli.

Influence of Proppant-Pillar Distance. As mentioned previously, if the distance between proppant pillars is too small, there could be no highly conductive channel network. On the other hand, if the separation of pillars is too large, the fracture might close under confining stress. This implies that there is an optimal pillar distance that leads to a maximum fracture conductivity. To identify this optimal pillar distance, various simulations were run with distances between pillars of $1,1.5,2,2.5,3$, and $3.5 \mathrm{~m}$. The closure stress, Young's modulus, and Poisson's ratio were maintained constant at $50 \mathrm{MPa}, 30 \mathrm{GPa}$, and 0.28 , respectively.

The contour plots in Fig. 19 shows that fracture width decreases with increasing pillar distance because of the reduced support to the fracture surfaces. When the pillar distance is $1 \mathrm{~m}$, the nearby pillars largely contact each other; as a result, the channels between the pillars become "dead" channels. When the pillar distance increases to from 1.5 to $3.5 \mathrm{~m}$, the fracture width increases approximately twofold. These results clearly demonstrate the significant influence of proppant-pillar separation on fracture width; this cannot be ignored when predicting fracture conductivity.

Fig. 20 shows fracture-width distribution along Line AB (refer to Fig. 9b) with different pillar separations. When the pillar distance is $1 \mathrm{~m}$, the adjacent pillars contact each other, so the open channels of the contact area are closed and the fracture width is changed to zero. These results once again demonstrate the significant influence of proppant-pillar separation on fracture width. Fig. 20 also indicates that fracture width becomes less uniform as the pillar distance decreases.

Fig. 21 shows fracture conductivity for different pillar diameters and pillar distances. For a specific pillar diameter, fracture conductivity first increases and then decreases as the pillar separation increases. The optimal pillar separations for different pillar diameters are reported in Table 3. The results indicate that the optimal ratio of pillar diameter to pillar distance for channel fracturing is approximately 0.6 to 0.7 , regardless of the diameter of the proppant pillar.

After obtaining the optimal proppant-pillar separation, the pulse time for pumping PFF can be determined. Fig. 22 shows a regular distribution of four proppant pillars. It shows that pillar distance $(2 l-2 r)$ relates to the total volume of PFF geometrically, whereas the pulse time of PFF determines the total volume of PFF physically. By expressing the volume of PFF, Eq. 30 shows the relationship between the pulse time of PFF and the distance between the pillars (Hou et al. 2016a), 


$$
\frac{4 Q t}{N \eta}=w\left(16 l^{2}-4 \pi r^{2}\right)
$$

where $l$ is the half-length of one-quarter of the calculation unit (see Fig. 22) (in mm).

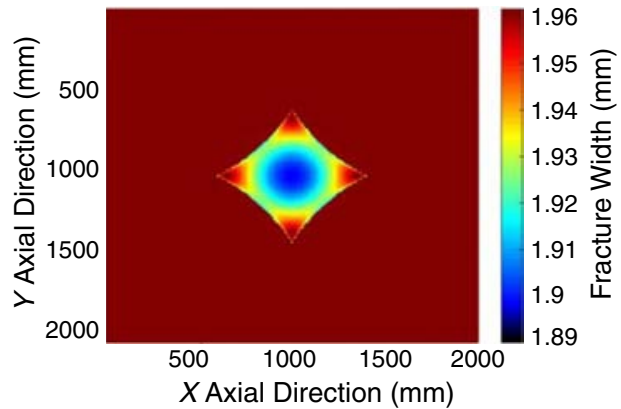

(a) Proppant-pillar distance $=1 \mathrm{~m}$

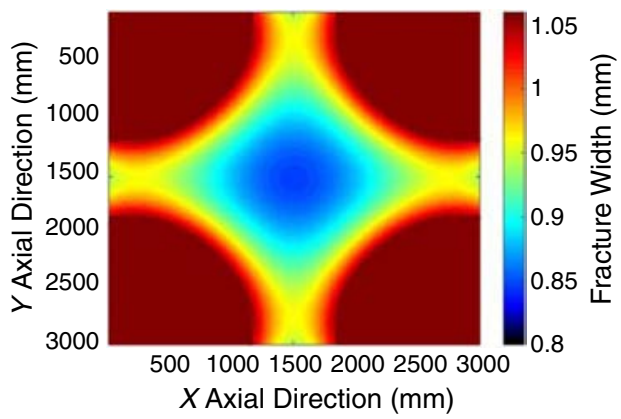

(c) Proppant-pillar distance $=2 \mathrm{~m}$

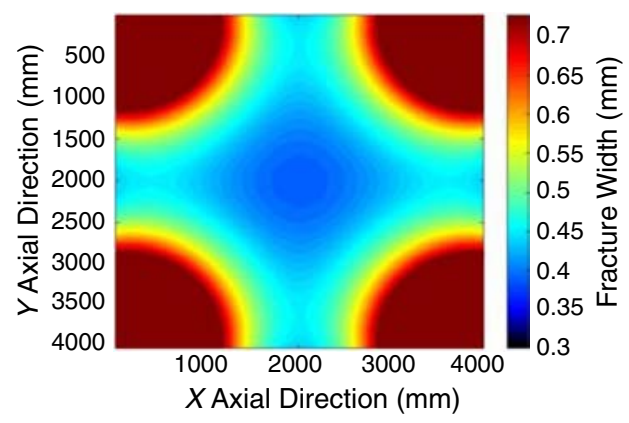

(e) Proppant-pillar distance $=3 \mathrm{~m}$

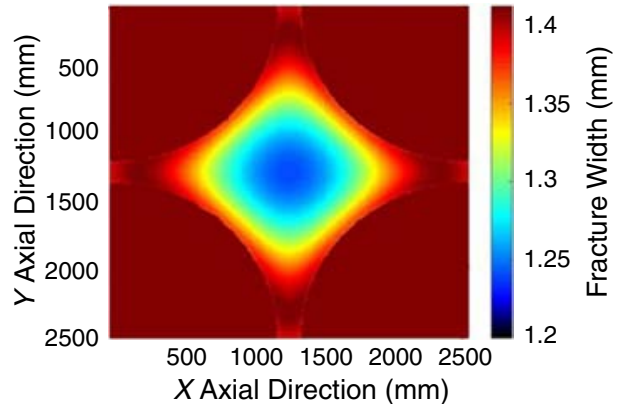

(b) Proppant-pillar distance $=1.5 \mathrm{~m}$

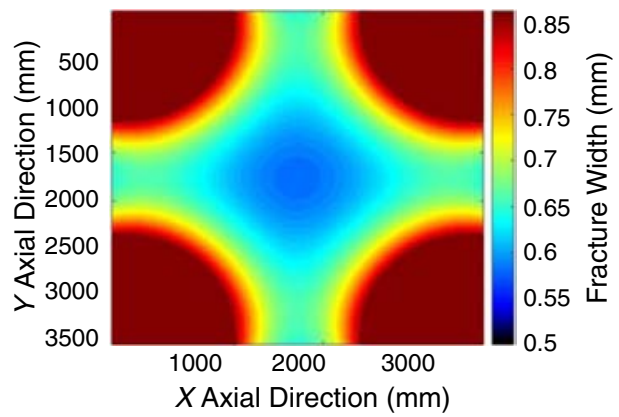

(d) Proppant-pillar distance $=2.5 \mathrm{~m}$

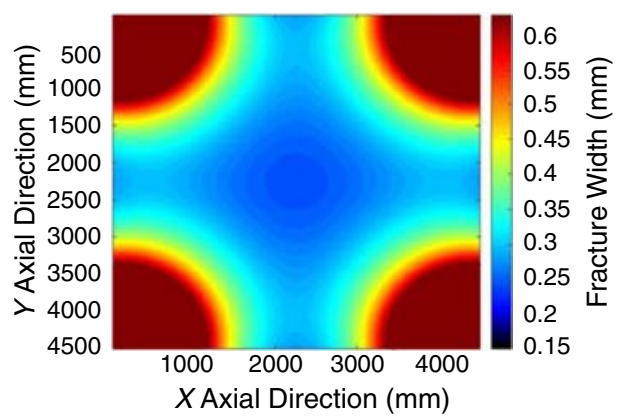

(f) Proppant-pillar distance $=3.5 \mathrm{~m}$

Fig. 19-Fracture width with different proppant-pillar distances. (a) Proppant-pillar distance = $1 \mathrm{~m}$; (b) proppant-pillar distance = $1.5 \mathrm{~m}$; (c) proppant-pillar distance $=2 \mathrm{~m}$; (d) proppant-pillar distance $=2.5 \mathrm{~m}$; (e) proppant-pillar distance $=3 \mathrm{~m}$; (f) proppant-pillar distance $=3.5 \mathrm{~m}$.

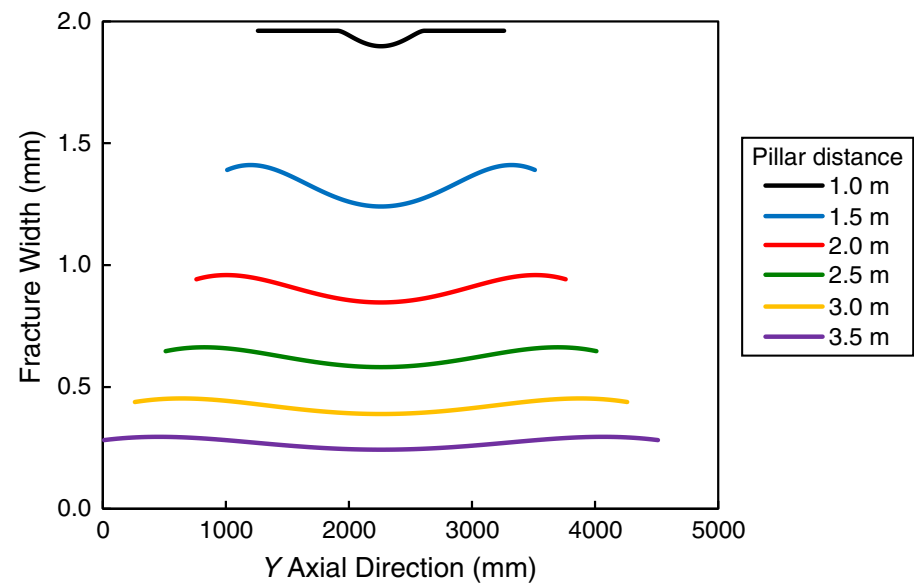

Fig. 20-Fracture width along the center Line AB (as shown in Figs. 16 and 19) with different pillar distances. 


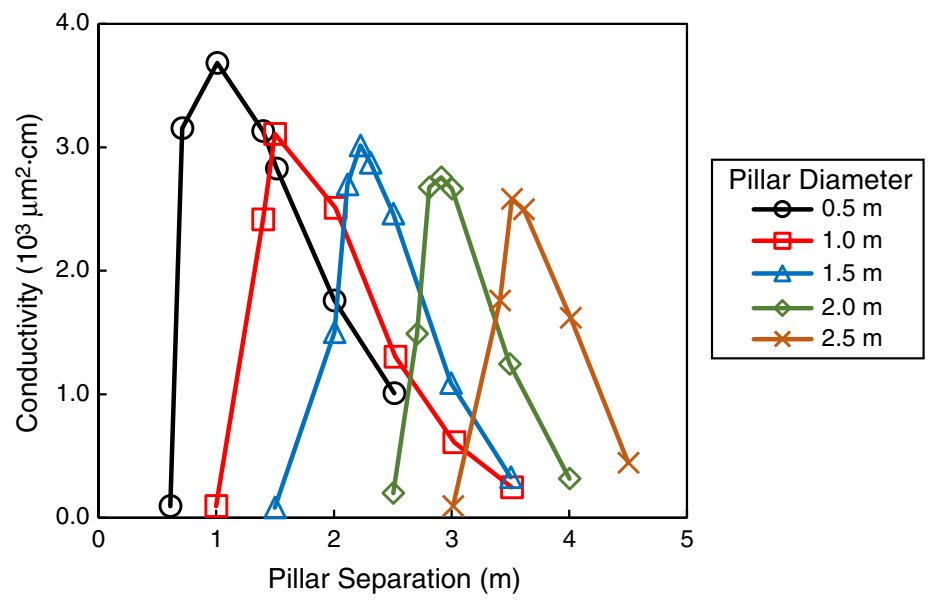

Fig. 21-Fracture conductivity for different proppant-pillar separations and diameters.

\begin{tabular}{ccc}
$\begin{array}{c}\text { Pillar } \\
\text { Diameter }(\mathrm{m})\end{array}$ & $\begin{array}{c}\text { Optimal Pillar } \\
\text { Separation }(\mathrm{m})\end{array}$ & $\begin{array}{c}\text { Pillar-Diameter/Pillar- } \\
\text { Separation Ratio } \gamma\end{array}$ \\
\hline 0.5 & $0.7-1.4$ & $0.36-0.71$ \\
1 & $1.4-2$ & $0.5-0.71$ \\
1.5 & $2-2.5$ & $0.6-0.75$ \\
2 & $2.8-3.5$ & $0.57-0.74$ \\
2.5 & $3.5-4.0$ & $0.63-0.74$ \\
\hline
\end{tabular}

Table 3-Optimal pillar separations for different pillar diameters.

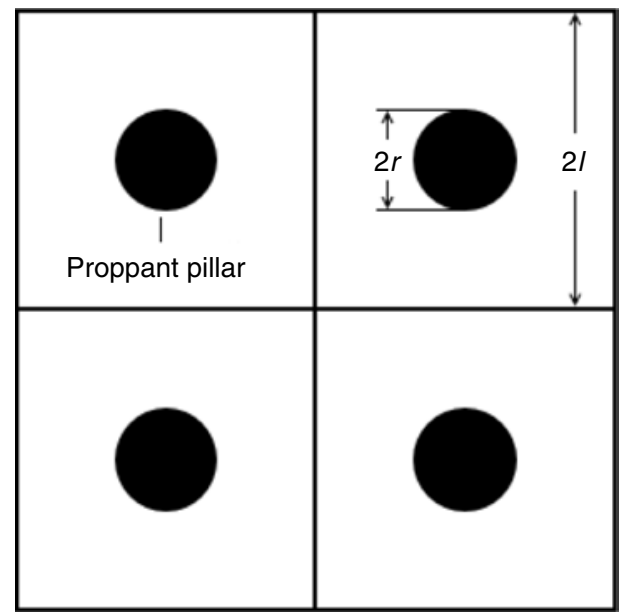

Fig. 22-A calculation unit for determining proppant-pillar distance or pulse time of fluid pumping.

\section{Discussion}

Fig. 23 compares fracture width calculated from different analytical methods under different closure stresses. As previously discussed, Hou's model (Hou et al. 2016a) and Zheng's model (Zheng et al. 2017) ignore the axial and radial strains of the pillar under closure stress. The results show that these two models significantly overestimate the fracture width. This implies that the axial and radial deformations of the proppant pillar, caused by particle rearrangement and appearing immediately after fracturing jobs, are the mostinfluential factors for fracture width. The Yan et al. (2016) model incorporates a linear-elastic constitutive model (Hooke's law) for the proppant pillar, which still overestimates the fracture width but to a smaller extent compared with the models that ignore proppantpillar deformation.

Fig. 24 shows the relative contributions of the three main deformation components (i.e., nonlinear deformation of proppant pillar, proppant embedment, and uneven deformation of the fracture surface in the high-conductivity channels) under different closure stresses. Results indicate that nonlinear deformation of the proppant pillar is the most-influential factor, whereas the embedment and fracture-surface deformation have limited effects on final fracture width. The nonlinear proppant-pillar deformation is far more important than realized in preceding studies.

Currently, when design calculations are performed, the ratio $(\tau)$ of the formation's Young's modulus to closure stress (usually the minimum horizontal stress) is used to evaluate the applicability of channel fracturing in a particular formation,

$$
\tau=\frac{E_{r}}{\sigma_{\min }}
$$




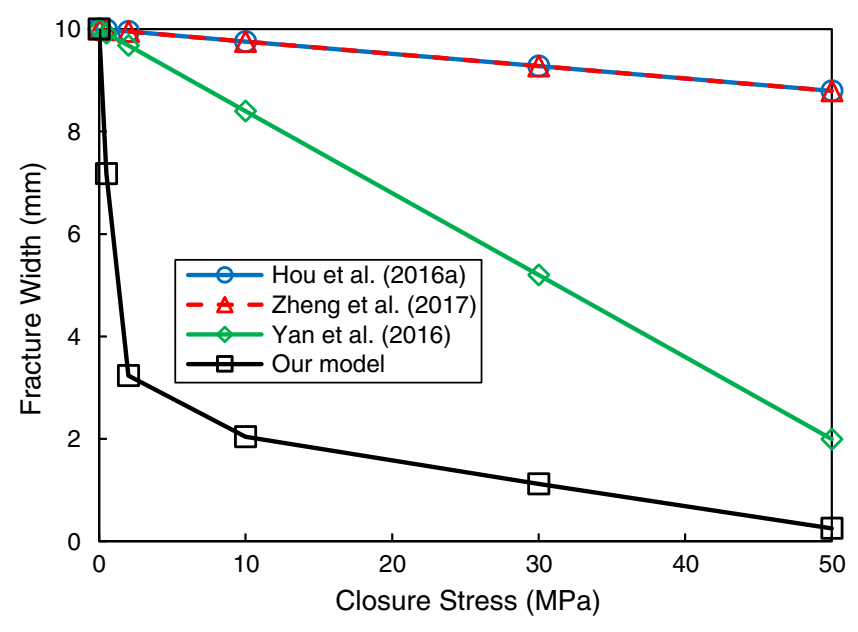

Fig. 23-Comparison of fracture width between different models.

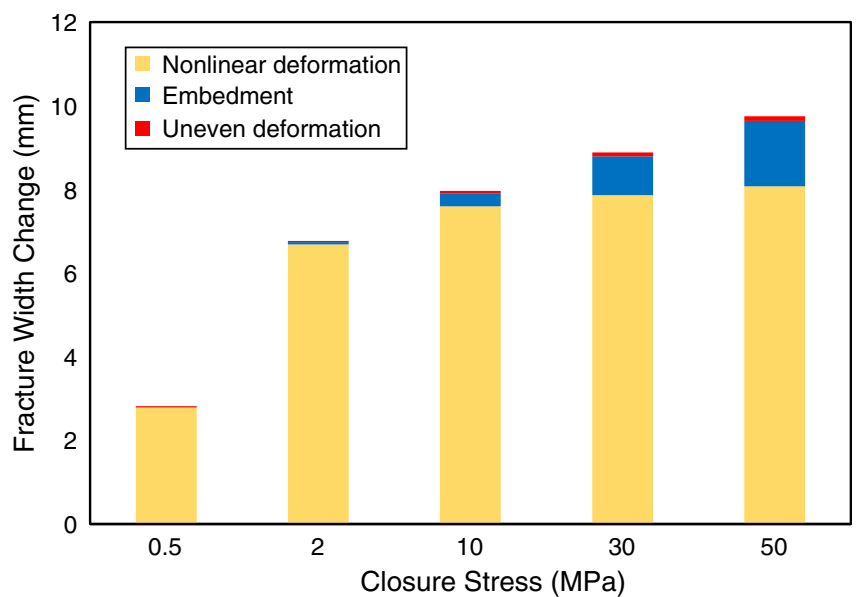

Fig. 24-Fracture-width change contributed by three main deformation components: nonlinear deformation of proppant pillar, proppant embedment, and uneven deformation of the fracture surface.

Schlumberger (2012) recommends that channel-fracturing technology is applicable when $\tau>275$. The values of $\tau$ for formations in various oil fields have been reported in the literature, such as 280 in Eagle Ford Shale (Rhein et al. 2011 ), 287 in Zagorskoe Field (Kayumov et al. 2014), 293 in the Barnett Shale Formation (Samuelson et al. 2012), 312 in Taylakovskoe Field (Sadykov et al. 2012), 419 and 556 in western Egypt (Gawad et al. 2013; Emam et al. 2014), 532 in the Ordos Basin (Li et al. 2015a), 583 in Jonah Field (Turner et al. 2011), 797 in the Burgos Basin (Valenzuela et al. 2012), and 632 in the Shengli Oil Field. All these fields have a $\tau$-value greater than 275, and channel-fracturing stimulations generally lead to more than a $30 \%$ increase in production.

However, in this study, it was determined that proppant-pillar distance is another critical factor that affects the feasibility of channel-fracturing technology, in addition to Young's modulus and closure stress. The pillar separation can control whether effective channels can form in the fracture. Effective channels might disappear because of contact between pillars when pillar separation is small (Fig. 25a) or because of fracture closure when pillar separation is larger (Fig. 25b).

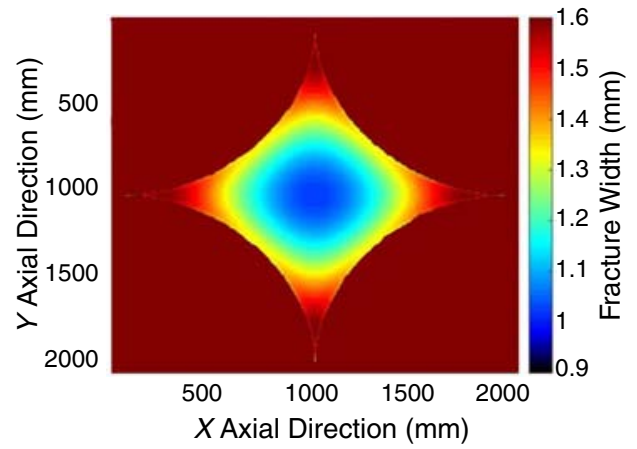

(a) Proppant-pillar contact

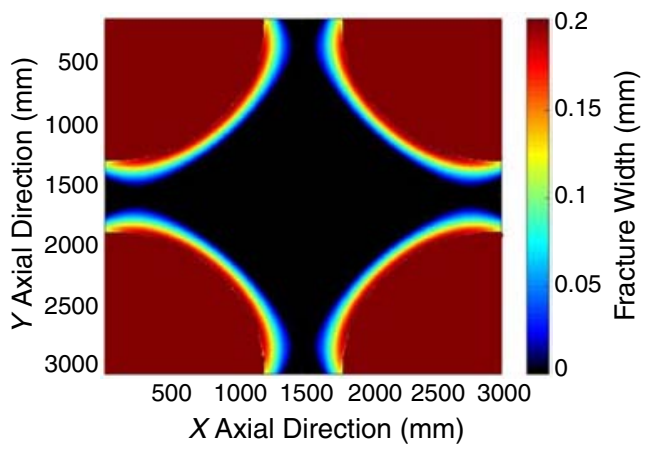

(b) Fracture closure in the middle area

Fig. 25-Two conditions leading to the loss of effective channels. (a) Proppant-pillar contact; (b) fracture closure in the middle area. 
Therefore, a successful channel-fracturing treatment should have at least two prerequisites: a sufficient ratio of Young's modulus to closure stress, and an appropriate pillar separation to avoid pillar interaction or fracture closure.

Fig. 26 shows the critical Young's modulus and critical ratio $(\tau)$ for different pillar diameters, pillar separations, and closure stresses. The solid and dashed lines in Fig. 26 show the critical Young's modulus and critical modulus to stress ratio $\tau$, respectively. The simulation results indicate that for the same pillar diameter and separation, the critical modulus increases with an increase of closure stress. As the pillar diameter increases, the critical pillar separation and modulus to stress ratio $\tau$ both increase. Therefore, in channel-fracturing treatments, the shorter the pulse time (i.e., the smaller the pillar dimeter), the greater the propped stability of the fracture.

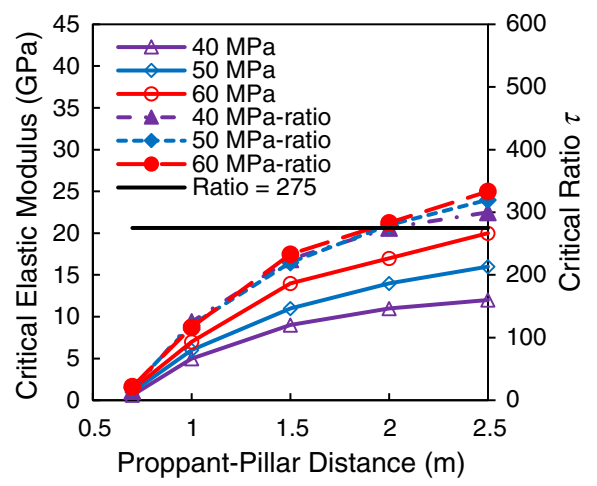

(a) Proppant-pillar diameter $=0.5 \mathrm{~m}$

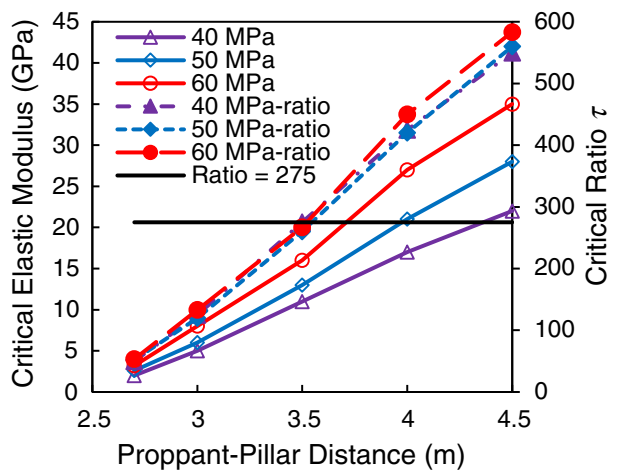

(c) Proppant-pillar diameter $=1.5 \mathrm{~m}$

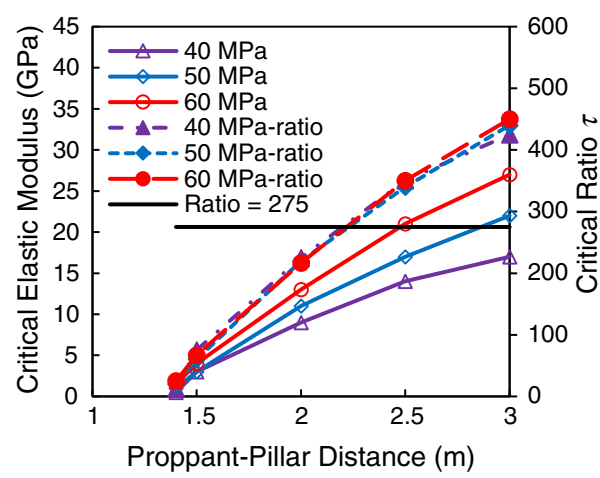

(b) Proppant-pillar diameter $=1 \mathrm{~m}$

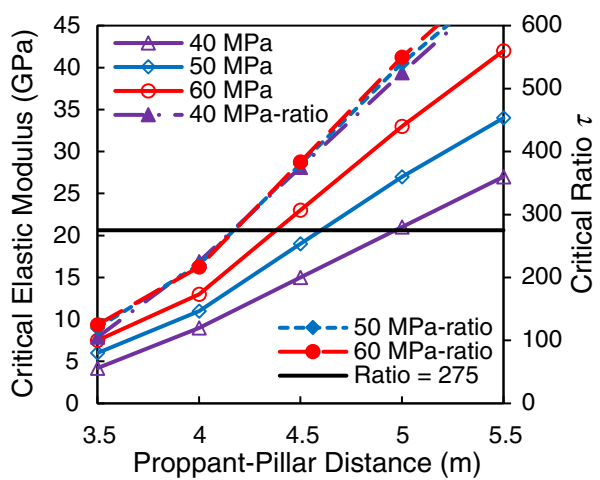

(d) Proppant-pillar diameter $=2 \mathrm{~m}$

Fig. 26-Critical rock modulus and critical ratio $\tau$ for channel fracturing. (a) Proppant-pillar diameter $=0.5 \mathrm{~m}$; (b) proppant-pillar diameter $=1 \mathrm{~m}$; (c) proppant-pillar diameter $=1.5 \mathrm{~m}$; (d) proppant-pillar diameter $=2 \mathrm{~m}$.

When the pillar diameter is $0.5 \mathrm{~m}$ (Fig. 26), the critical pillar separation is 0.7 to $1.9 \mathrm{~m}$ and the critical ratio $\tau$ is always smaller than 275; however, the fracture can still be effectively propped with proppant pillars. This implies that the application of channel fracturing can be extended and that the critical value of $\tau$ currently used in the industry (275) is somewhat conservative, and might limit the application of the channel-fracturing technology.

In summary, it might not be appropriate to evaluate the feasibility of channel fracturing using only the value of $\tau$. Instead, the geomechanical parameters of the formation and the operational parameters of the fracturing treatment should be considered in an integrated manner. In fracturing treatments, the nominal proppant-pillar separation can be altered by manipulating the pulse-pumping time to extend the application of this technology. However, the pulse time must be large enough to avoid pillar contact.

Finally, an actual field example of channel fracturing is provided to illustrate the effectiveness of this technology. Channelfracturing treatments were used in three wells in Block X171 in Shengli Oil Field in China. The formation properties and operational parameters were summarized in Table 4. Channel-fracturing stimulation was used in Wells X171-4VF and X171-3VF. The performance of an offset well, Well X171-7VF, with conventional fracturing treatment was used as a baseline comparison. The perforation density in these wells is 16 shots $/ \mathrm{m}$, the effective-perforation ratio is 0.8 , the fracture width is $0.005 \mathrm{~m}$, and the pillar diameter is $2 \mathrm{~m}$. The designed pillar separation and pulse time for each well are provided in Table 4. Fig. 27 shows the cumulative oil productions of the wells with channel-fracturing treatment and the reference well treated with a conventional fracturing treatment. In this instance, the comparison demonstrates that the wells treated with channel fracturing have a $40 \%$ higher production than the conventionally fractured well.

\begin{tabular}{|c|c|c|c|c|c|c|c|c|c|c|c|c|}
\hline Well No. & $\begin{array}{c}\text { Elastic } \\
\text { Modulus } \\
(\mathrm{GPa})\end{array}$ & $\tau$ & $\begin{array}{l}\text { Play } \\
\text { Height } \\
\text { (m) }\end{array}$ & $\begin{array}{l}\text { Permeability } \\
\text { (md) }\end{array}$ & $\begin{array}{l}\text { Proppant } \\
\text { Volume } \\
\left(\mathrm{m}^{3}\right)\end{array}$ & $\begin{array}{l}\text { Pulse } \\
\text { Numbers }\end{array}$ & $\begin{array}{c}\text { Pumping } \\
\text { Rate } \\
\text { ( } \mathrm{m}^{3} / \mathrm{min} \text { ) }\end{array}$ & $\begin{array}{l}\text { Average } \\
\text { Perforation } \\
\text { Height }(\mathrm{m})\end{array}$ & $\begin{array}{l}\text { Optimal } \\
\text { Pillar } \\
\text { Distance } \\
\text { (m) }\end{array}$ & $\begin{array}{l}\text { PLF Time } \\
\text { (minutes) }\end{array}$ & $\begin{array}{l}\text { Calculated } \\
\text { PFF Time } \\
\text { (minutes) }\end{array}$ & $\begin{array}{l}\text { Field PFF } \\
\text { Time } \\
\text { (minutes) }\end{array}$ \\
\hline X171-4VF & 34 & 653 & 30.7 & 152.777 & 21 & 11 & 6 & 3.2 & $2.2-2.4$ & 2 & $1.7-1.9$ & 1.8 \\
\hline X171-3VF & 34 & 653 & 51.5 & 230 & 23.4 & 11 & 6 & 3.4 & $2.1-2.6$ & 2 & $1.8-2.2$ & 1.8 \\
\hline $\mathrm{X} 171-7 \mathrm{VF}$ & - & - & 30.7 & 82.985 & 82 & - & 6 & 3.4 & - & - & - & - \\
\hline
\end{tabular}

Table 4-Formation properties and stimulation parameters of three wells in Block X171 in Shengli Oil Field, China. 


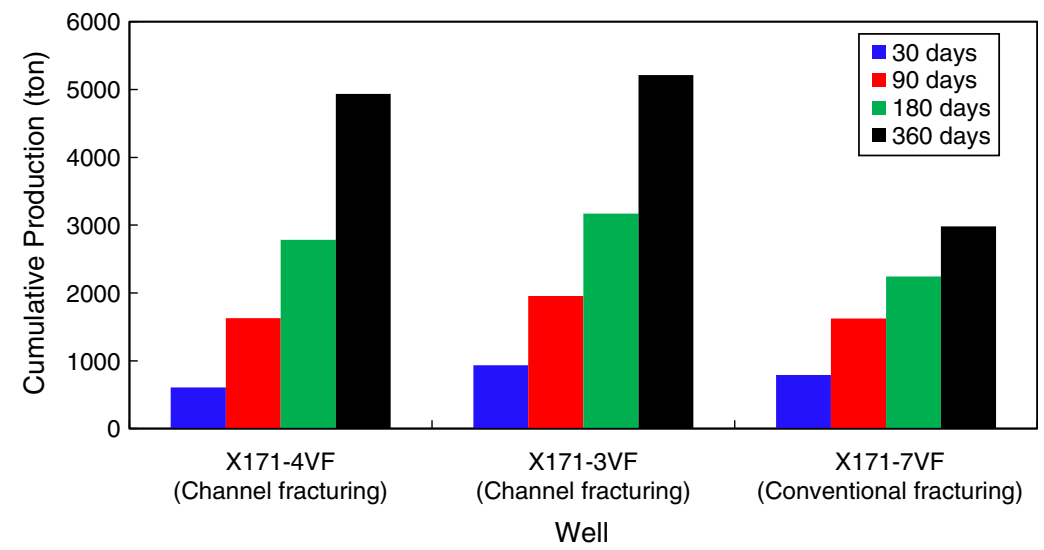

Fig. 27-Cumulative oil production of wells with channel-fracturing treatments and a well with a conventional fracturing treatment.

\section{Conclusions}

The experimental study on proppant pillars shows that the axial and radial deformations of generic proppant pillars increase more rapidly during early loading time and more slowly at higher stresses, indicating a clear compaction process. Nonlinear, piecewise constitutive equations describing axial stress and strain in proppant pillars were established from experimental measurements.

A mathematical model was developed to predict fracture width and conductivity, taking into account the deformation of the proppant pillars and the fracture surfaces. The model captures the realistic deformation behavior of proppant pillars and the fracture while the pillars are loaded by the in-situ stress.

Fracture width, volume, and conductivity are strong functions of closure stress. As the effective-closure stress increases, fracture volume and conductivity decrease predictably. The sensitivity of fracture conductivity to closure stress is more obvious when the applied stress is relatively low. This occurs when the effective stress is high (limited drawdown).

Fracture conductivity increases with an increase in the formation's Young's modulus, although the influence of Young's modulus is relatively small compared with the influence of the closure stress. The fracture opening is also less uniform with a smaller value of Young's modulus.

Fracture width also decreases as the proppant-pillar separation increases. For specific proppant-pillar parameters and formation conditions, there is an optimal pillar separation that results in a maximum fracture conductivity.

It is not sufficient to evaluate the applicability of channel fracturing according to geomechanical parameters of the target formation only. Appropriate adjustment of the pulse-injection time can extend the application of this technology.

\section{Nomenclature}

$a=$ change of distance between the centers of two spheres, $\mathrm{m}$

$a_{1}=$ change of distance between the center of a sphere and a deformable surface of a plane, $\mathrm{m}$

$a_{2}=$ deformation of Sphere 1 when it meets a rigid plane, $\mathrm{m}$

$A=$ cross-sectional area of flow region, $\mathrm{mm}^{2}$

$c=$ distance between the center of loaded area and investigated spot, $\mathrm{mm}$

$c_{i}=$ distance between point $M$ and the center of the pillar $i, \mathrm{~mm}$

$C=$ Kozeny-Carman coefficient, dimensionless

$C_{E}=$ a temporary parameter, $\mathrm{Pa}^{-1}$

$d_{i}=$ proppant-pillar diameter at segment $i, \mathrm{~mm}$

$d_{i-1}=$ proppant-pillar diameter at segment $i-1, \mathrm{~mm}$

$d_{0}=$ initial pillar diameter, $\mathrm{mm}$

$\mathrm{d} p / \mathrm{d} x=$ flow pressure gradient along the $x$-direction in the fracture, $\mathrm{Pa} / \mathrm{mm}$

$D_{1}=$ diameter of Sphere $1, \mathrm{~m}$

$E_{p}=$ elastic modulus of proppant pillar, $\mathrm{MPa}$

$E_{p r}=$ elastic modulus of proppant particles, MPa

$E_{r}=$ elastic modulus of rock, MPa

$E_{1}=$ elastic modulus of Sphere $1, \mathrm{~Pa}$

$E_{2}=$ elastic modulus of Sphere $2, \mathrm{~Pa}$

$F=$ fracture conductivity, $\mu \mathrm{m}^{2} \cdot \mathrm{cm}$

$h_{i}=$ proppant-pillar height at segment $i, \mathrm{~mm}$

$h_{i-1}=$ proppant-pillar height at segment $i-1, \mathrm{~mm}$

$h_{0}=$ initial pillar height, $\mathrm{mm}$

$k=$ fracture permeability, $\mathrm{mm}^{2}$

$k_{c}=$ permeability of open channel, $\mathrm{mm}^{2}$

$k_{\text {eq }}=$ equivalent permeability of Regions 1,2 , and $3, \mathrm{~mm}^{2}$

$k_{\text {eq }}^{\prime}=$ equivalent permeability of Regions 1 and $2, \mathrm{~mm}^{2}$

$k_{p}=$ permeability of proppant pillar, $\mathrm{mm}^{2}$

$K=$ distance variance, dimensionless

$m=$ number of total proppant pillars in fracture-unit area, dimensionless

$m_{p}=$ mass of one proppant pillar, $\mathrm{kg}$

$n=$ number of segments into which the stress/strain curve is cut, dimensionless

$N=$ total perforation number, dimensionless

$P=$ external force on two spheres, $\mathrm{N}$ 
$Q=$ flow rate of fracturing fluid, $\mathrm{mm}^{3} / \mathrm{s}$

$r=$ pillar radius, $\mathrm{mm}$

$R=$ radius of proppant particles, $\mathrm{mm}$

$R_{1}=$ radius of Sphere $1, \mathrm{~m}$

$R_{2}=$ radius of Sphere $2, \mathrm{~m}$

$s=$ temporary length used for calculating subsidence of investigated spot, $\mathrm{mm}$

$t=$ pulse time of channel fracturing, seconds

$v_{p}=$ Poisson's ratio of proppant pillar, dimensionless

$v_{p r}=$ Poisson's ratio of proppant particles, dimensionless

$v_{r}=$ Poisson's ratio of rock, dimensionless

$v_{1}=$ Poisson's ratio of Sphere 1, dimensionless

$v_{2}=$ Poisson's ratio of Sphere 2, dimensionless

$V_{p}=$ volume of one proppant pillar, $\mathrm{mm}^{3}$

$w=$ fracture width, $\mathrm{mm}$

$\alpha=$ subsidence of the loaded area in a loaded half-space plane, $\mathrm{mm}$

$\beta=$ subsidence outside the loaded area in a loaded half-space plane, $\mathrm{mm}$

$\gamma=$ ratio of pillar radius to fracture unit length, dimensionless

$\delta=$ change of fracture width caused by subsidence, $\mathrm{mm}$

$\delta_{1}=$ fracture-surface deformation, $\mathrm{mm}$

$\delta_{2}=$ proppant embedment of the pillar, $\mathrm{mm}$

$\Delta h=$ axial deformation of proppant pillar, $\mathrm{mm}$

$\Delta \varepsilon=$ axial-strain difference, dimensionless

$\Delta \zeta=$ radial-strain difference, dimensionless

$\Delta \sigma=$ stress difference, $\mathrm{MPa}$

$\eta=$ effective-perforation ratio, dimensionless

$\theta=$ temporary angle used for calculating subsidence of investigated spot, dimensionless

$\mu=$ dynamic viscosity, $\mathrm{Pa} \cdot \mathrm{s}$

$\rho_{f}=$ density of proppant-laden fluid, $\mathrm{kg} / \mathrm{mm}^{3}$

$\rho_{p}=$ density of proppant pillar, $\mathrm{kg} / \mathrm{mm}^{3}$

$\rho_{p r}=$ density of proppant particles, $\mathrm{kg} / \mathrm{mm}^{3}$

$\sigma=$ closure stress, $\mathrm{MPa}$

$\sigma_{i}=$ closure stress at segment $i, \mathrm{MPa}$

$\sigma_{i-1}=$ closure stress at segment $i-1, \mathrm{MPa}$

$\sigma_{\min }=$ minimum horizontal stress, $\mathrm{MPa}$

$\tau=$ ratio of rock elastic modulus to minimum horizontal stress, dimensionless

$\phi=$ porosity of proppant pillar, dimensionless

$\psi=$ temporary angle used for calculating subsidence of investigated spot, dimensionless

$\omega=$ subsidence in a loaded half-space plane, $\mathrm{mm}$

\section{Acknowledgments}

This work was funded by the National Natural Science Foundation of China (Grant Nos. 51604232, 51874253, 11872363, and 51861145314), the China Postdoctoral Science Foundation (Grant Nos. 2017M610117 and 2018T110142), the Search Foundation of Sichuan Province (Grant No. 2018FZ0069), the Chinese Academy of Sciences (CAS) through the CAS Interdisciplinary Innovation Team Project, the CAS Key Research Program of Frontier Sciences (Grant No. QYZDJ-SSW449JSC019), and the CAS Strategic Priority Research Program (Grant No. XDB22040401).

\section{References}

API RP 61, Recommended Practices for Evaluating Short Term Proppant Pack Conductivity. 1989. Washington, DC: American Petroleum Institute.

Asgian, M. I., Cundall, P. A., and Brady, B. H. G. 1995. The Mechanical Stability of Propped Hydraulic Fractures: A Numerical Study. J Pet Technol 47 (3): 203-208. SPE-28510-PA. https://doi.org/10.2118/28510-PA.

Bear, J. 1972. Dynamics of Fluids in Porous Media. New York City: Elsevier.

Bolintineanu, D. S., Rao, R. R., Lechman, J. B. et al. 2017. Simulations of the Effects of Proppant Placement on the Conductivity and Mechanical Stability of Hydraulic Fractures. Int J Rock Mech Min Sci 100 (December): 188-198. https://doi.org/10.1016/j.ijrmms.2017.10.014.

Cleary, M. P. 1994. Critical Issues in Hydraulic Fracturing of High-Permeability Reservoirs. Presented at European Production Operations Conference and Exhibition, Aberdeen, 15-17 March. SPE-27618-MS. https://doi.org/10.2118/27618-MS.

Emam, M., Knight, R., Bezboruah, P. et al. 2014. Novel Hydraulic Fracturing Technique Application in Egypt. Presented at Abu Dhabi International Petroleum Exhibition and Conference, Abu Dhabi, 10-13 November. SPE-172106-MS. https://doi.org/10.2118/172106-MS.

Gao, Y., Lv, Y., Wang, M. et al. 2013. New Mathematical Models for Calculating the Proppant Embedment and Conductivity. Presented at International Petroleum Technology Conference, Beijing, 26-28 March. IPTC-16410-MS. https://doi.org/10.2523/IPTC-16410-MS.

Gawad, A. A., Long, J., El-Khalek, T. et al. 2013. Novel Combination of Channel Fracturing With Rod-Shaped Proppant Increases Production in the Egyptian Western Desert. Presented at the SPE European Formation Damage Conference and Exhibition, Noordwijk, The Netherlands, 5-7 June. SPE-165179-MS. https://doi.org/10.2118/165179-MS.

Gillard, M. R., Medvedev, O. O., Hosein, P. R. et al. 2010. A New Approach to Generating Fracture Conductivity. Presented at the SPE Annual Technical Conference and Exhibition, Florence, Italy, 20-22 September. SPE-135034-MS. https://doi.org/10.2118/135034-MS.

Guo, J. C., Wang, J. D., Liu, Y. X. et al. 2017. Analytical Analysis of Fracture Conductivity for Sparse Distribution of Proppant Packs. J Geophys Eng 14 (3): 599-610. https://doi.org/10.1088/1742-2140/aa6215.

Hou, B., Zheng, X., Chen, M. et al. 2016b. Parameter Simulation and Optimization in Channel Fracturing. J Nat Gas Sci Eng 35A (September): 122-130. https://doi.org/10.1016/j.jngse.2016.08.046.

Hou, T. F., Zhang, S. C., Yu, B. H. et al. 2016a. Theoretical Analysis and Experimental Research of Channel Fracturing in Unconventional Reservoir. Presented at SPE Europec featured at 78th EAGE Conference and Exhibition, Vienna, Austria, 30 May-2 July. SPE-180105-MS. https://doi.org/10.2118/180105-MS. 
Johnson, K. L. 1985. Contact Mechanics. Cambridge, UK: Cambridge University Press.

Kayumov, R., Klyubin, A., Konchenko, A. et al. 2014. Channel Fracturing Enhanced by Unconventional Proppant Increases Effectiveness of Hydraulic Fracturing in Devonian Formations of Russia's Oilfields. Presented at the International Petroleum Technology Conference, Doha, 19-22 January. IPTC-17409-MS. https://doi.org/10.2523/IPTC-17409-MS.

Kayumov, R. E., Klyubin, A., Yudin, A. V. et al. 2012. First Channel Fracturing Applied in Mature Wells Increases Production From Talinskoe Oilfield in Western Siberia. Presented at the SPE Russian Oil \& Gas Exploration \& Production Technical Conference and Exhibition, Moscow, 16-18 October. SPE-159347-MS. https://doi.org/10.2118/159347-MS.

Li, A. Q., Mu, L. J., Li, X. W. et al. 2015a. The Channel Fracturing Technique Improves Tight Reservoir Potential in the Ordos Basin, China. Presented at the SPE/IATMI Asia Pacific Oil \& Gas Conference and Exhibition, Bali, Indonesia, 20-22 October. https://doi.org/10.2118/176071-MS

Li, K., Gao, Y., Lyu, Y. et al. 2015b. New Mathematical Models for Calculating Proppant Embedment and Fracture Conductivity. SPE J. 20 (3): 496-507. SPE-155954-PA. https://doi.org/10.2118/155954-PA.

Meyer, B., Bazan, L. W., Walls, D. et al. 2014. Theoretical Foundation and Design Formulae for Channel and Pillar Type Propped Fractures-A Method to Increase Fracture Conductivity. Presented at the SPE Annual Technical Conference and Exhibition, Amsterdam, 27-29 October. SPE-170781-MS. https://doi.org/10.2118/170781-MS.

Nguyen, P. D., Vo, L. K., Parton, C. et al. 2014. Evaluation of Low-Quality Sand for Proppant-Free Channel Fracturing Method. Presented at the International Petroleum Technology Conference, Kuala Lumpur, 10-12 December. IPTC-17937-MS. https://doi.org/10.2523/IPTC-17937-MS.

Rhein, T., Loayza, M. P., Kirkham, B. et al. 2011. Channel Fracturing in Horizontal Wellbores: The New Edge of Stimulation Techniques in the Eagle Ford Formation. Presented at the SPE Annual Technical Conference and Exhibition, Denver, 30 October-2 November. SPE-145403-MS. https:// doi.org/10.2118/145403-MS.

Sadykov, A., Yudin, A. V., Oparin, M. et al. 2012. Channel Fracturing in the Remote Taylakovskoe Oil Field: Reliable Stimulation Treatments for Significant Production Increase. Presented at the SPE Russian Oil and Gas Exploration and Production Technical Conference and Exhibition, Moscow, 16-18 October. SPE-160767-MS. https://doi.org/10.2118/160767-MS.

Samuelson, M. L., Stefanski, J., Downie, R. et al. 2012. Field Development Study: Channel Hydraulic Fracturing Achieves Both Operational and Productivity Goals in the Barnett Shale. Presented at the SPE Americas Unconventional Resources Conference, Pittsburgh, Pennsylvania, 5-7 June. SPE155684-MS. https://doi.org/10.2118/155684-MS.

Schlumberger. 2012. HiWAY: The Quest for Infinite Conductivity Innovation for a Step-Change in Hydraulic Fracturing. Presentation, Jornada De Maxi-Fracturas, May 2012. http://www.oilproduction.net/cms3/files/Villarreal.pdf.

Tang, Y., Ranjinth, P. G., Perera, M. S. A. et al. 2018. Influences of Proppant Concentration and Fracturing Fluids on Proppant-Embedment Behavior for Inhomogeneous Rock Medium: An Experimental and Numerical Study. SPE Prod \& Oper 33 (4): 666-678. SPE-189984-PA. https://doi.org/ 10.2118/189984-PA.

Turner, M. G, Weinstock, C. T., Laggan, M. J. et al. 2011. Raising the Bar in Completion Practices in Jonah Field: Channel Fracturing Increases Gas Production and Improves Operational Efficiency. Presented at the Canadian Unconventional Resources Conference, Calgary, 15-17 November. SPE147587-MS. https://doi.org/10.2118/147587-MS.

Valenzuela, A., Guzmán, J., Chávez, S. et al. 2012. Field Development Study: Channel Fracturing Increases Gas Production and Improves Polymer Recovery in Burgos Basin, Mexico North. Presented at the SPE Hydraulic Fracturing Technology Conference, The Woodlands, Texas, 6-8 February. SPE-152112-MS. https://doi.org/10.2118/152112-MS.

Valiullin, A., Vladimir, M., Yudin, A. et al. 2015. Channel Fracturing Technique Helps to Revitalize Brown Fields in Langepas Area. Presented at the SPE Oil and Gas India Conference and Exhibition, Mumbai, 24-26 November. SPE-178131-MS. https://doi.org/10.2118/178131-MS.

Wang, J. and Elsworth, D. 2018. Role of Proppant Distribution on the Evolution of Hydraulic Fracture Conductivity. J Pet Sci Eng 166 (July): $249-262$. https://doi.org/10.1016/j.petrol.2018.03.040.

Yan, X., Huang, Z., Yao, J. et al. 2016. Theoretical Analysis of Fracture Conductivity Created by the Channel-Fracturing Technique. J Nat Gas Sci Eng 31 (April): 320-330. https://doi.org/10.1016/j.jngse.2016.03.038.

Zhang, F., Zhu, H., Zhou, H. et al. 2017. Discrete-Element-Method/ Computational-Fluid-Dynamics Coupling Simulation of Proppant Embedment and Fracture Conductivity After Hydraulic Fracturing. SPE J. 22 (2): 632-644. SPE-185172-PA. https://doi.org/10.2118/185172-PA.

Zhang, J. 2014. Theoretical Conductivity Analysis of Surface Modification Agent Treated Proppant. Fuel 134 (15 October): 166-170. https://doi.org/ 10.1016/j.fuel.2014.05.031.

Zhang, J. and Hou, J. 2016. Theoretical Conductivity Analysis of Surface Modification Agent Treated Proppant II-Channel Fracturing Application. Fuel 165 (1 February): 28-32. https://doi.org/10.1016/j.fuel.2015.10.026.

Zheng, X., Chen, M., Hou, B. et al. 2017. Effect of Proppant Distribution Pattern on Fracture Conductivity and Permeability in Channel Fracturing. J Pet Sci Eng 149 (20 January): 98-106. https://doi.org/10.1016/j.petrol.2016.10.023.

Zhu, H., Shen, J., Zhang, F. et al. 2018. DEM-CFD Modeling of Proppant Pillar Deformation and Stability During the Fracturing Fluid Flowback. Geofluids 2018: 3535817. https://doi.org/10.1155/2018/3535817.

Zhu, H., Zhang, X., Guo, J. C. et al. 2015. Stress Field Interference of Hydraulic Fractures in Layered Formation. Geomech Eng 9 (5): 645-667. https:// doi.org/10.12989/gae.2015.9.5.645.

Zhu, H.-Y., Jin, X.-C., Guo, J.-C. et al. 2016. Coupled Flow, Stress and Damage Modelling of Interactions Between Hydraulic Fractures and Natural Fractures in Shale Gas Reservoirs. Int J Oil Gas Coal Tech 13 (4): 359-390. https://doi.org/10.1504/IJOGCT.2016.080095.

Haiyan Zhu is currently a professor in the State Key Laboratory of Oil and Gas Reservoir Geology and Exploitation, Chengdu University of Technology, China. He previously worked at the SINOPEC Jianghan Oilfield Company for 1 year between 2009 and 2010 and at Southwest Petroleum University for 5 years as an associate professor between 2013 and 2018 . Zhu's research interests are petroleum-related rock mechanics, including laboratory experiments and numerical simulation of wellbore drilling, reservoir stimulation, sand production, 4D geostress evolution, and rock breaking. He has authored or coauthored more than 50 academic papers. Zhu holds a PhD degree in petroleum-related rock mechanics and engineering from the China University of Petroleum, Beijing

Ya-Pu Zhao (corresponding author) is a professor of solid mechanics and physical mechanics at the Institute of Mechanics, Chinese Academy of Sciences and University of Chinese Academy of Sciences. His current research interests include hydraulic fracturing and adsorption and desorption of shale gas. Zhao holds a PhD degree in solid mechanics from Peking University, China.

Yongcun Feng (corresponding author) is a research associate in the Department of Petroleum and Geosystems Engineering at the University of Texas at Austin, where he performs research in drilling-and-completion-related geomechanics. Feng holds a $\mathrm{PhD}$ degree from the University of Texas at Austin and master's and bachelor's degrees from China University of Petroleum, Beijing, all in petroleum engineering. 
Haowei Wang is currently a master's-degree candidate at the State Key Laboratory of Oil and Gas Reservoir Geology and Exploitation at Southwest Petroleum University. His research interests include hydraulic-fracturing modeling and experiments.

Liaoyuan Zhang is currently a senior engineer at Sinopec Shengli Oilfield Company, China. His research interests are hydraulicfracturing modeling and field application. Zhang holds a master's degree in oilfield- and gasfield-development engineering from China University of Petroleum, East China.

John McLennan has been a Utah Science Technology and Research Initiative associate professor in the Department of Chemical Engineering at the University of Utah since 2009. He has been a senior research scientist at the Energy \& Geoscience Institute and an adjunct professor in the Department of Civil Engineering at the University of Utah since January 2008. McLennan has more than 35 years of experience with petroleum service and technology companies, including Dowell Schlumberger, TerraTek, Advantek International, and ASRC Energy Services. He holds a PhD degree in civil engineering from the University of Toronto, Canada. 